\title{
Production of highly efficient activated carbons from industrial wastes for the removal of pharmaceuticals from water - a full factorial design
}

\author{
Guilaine Jaria ${ }^{1}$, Carla Patrícia Silva ${ }^{1}$, João A.B.P. Oliveira ${ }^{1}$, Sérgio M. Santos ${ }^{2}$, María Victoria Gil ${ }^{3}$, \\ Marta Otero $^{4}$, Vânia Calisto ${ }^{1 *}$, Valdemar I. Esteves ${ }^{1}$ \\ ${ }^{1}$ Department of Chemistry \& CESAM, University of Aveiro, Campus de Santiago, 3810-193 \\ Aveiro, Portugal \\ ${ }^{2}$ Department of Chemistry \& CICECO, University of Aveiro, Campus de Santiago, 3810-193 \\ Aveiro, Portugal \\ ${ }^{3}$ Instituto Nacional del Carbón, INCAR-CSIC, Francisco Pintado Fe 26, \\ 33011 Oviedo, Spain \\ ${ }^{4}$ Department of Environment and Planning \& CESAM, University of Aveiro, Campus de Santiago, \\ 3810-193 Aveiro, Portugal \\ *vania.calisto@ua.pt
}

\begin{abstract}
The wide occurrence of pharmaceuticals in aquatic environments urges the development of cost-effective solutions for their removal from water. In a circular economy context, primary paper mill sludge (PS) was used to produce activated carbon (AC) aiming the adsorptive removal of these contaminants. The use of low-cost precursors for the preparation of ACs capable of competing with commercial ACs continues to be a challenge. A full factorial design of four factors (pyrolysis temperature, residence time, precursor/activating agent ratio, and type of activating agent) at two levels was applied to the production of AC using PS as precursor. The responses analysed were the yield of production, percentage of adsorption for three pharmaceuticals (sulfamethoxazole, carbamazepine, and paroxetine), specific surface area $\left(S_{\mathrm{BET}}\right)$, and total organic carbon.
\end{abstract}


Statistical analysis was performed to evaluate influencing factors in the responses and to determine the most favourable production conditions. Four ACs presented very good responses, namely on the adsorption of the pharmaceuticals under study (average adsorption percentage around $78 \%$, which is above that of commercial AC), and $S_{\mathrm{BET}}$ between 1389 and $1627 \mathrm{~m}^{2} \mathrm{~g}^{-1}$. A desirability analysis pointed out $800{ }^{\circ} \mathrm{C}$ for 60 minutes and a precursor/KOH ratio of $1: 1(w / w)$ as the optimal production conditions.

Keywords: Primary paper mill sludge, activated carbon, full factorial design, adsorption

\section{Introduction}

Pharmaceuticals are currently recognized as an important group of environmental contaminants that can affect the ecosystems, even at very low concentrations (ng L $\mathrm{L}^{-1}$ to $\mu \mathrm{g}$ $\mathrm{L}^{-1}$ level) [1-3]. The contamination of water systems by pharmaceuticals is mainly due to the inefficiency of primary and secondary treatments of wastewater treatment plants (WWTPs) to remove these compounds. The application of advanced tertiary treatments such as ultrafiltration, adsorption onto activated carbon (AC), and advanced oxidation processes (AOPs), is not generalized since those can be rather expensive [4-7]. European Union has already assumed the need of a new approach concerning aquatic pollution by pharmaceuticals and the development of low-cost strategies for water remediation [8].

$\mathrm{AC}$ is a versatile material that possesses high specific surface areas $\left(S_{\mathrm{BET}}\right)$ and unique surface chemistry properties showing, in general, good removal efficiencies towards organic compounds, without the formation of reaction by-products as it is the case, for instance, of AOPs [9-11]. The main limitation regarding the application of AC in WWTPs is the high cost of the available commercial ACs, for which the used precursors have a 
great contribution [12]. Therefore, the use of wastes (industrial and agricultural) as new resources to produce ACs is gaining increasing attention since it can be also an alternative management strategy, in line with the new paradigm of a circular and sustainable economy $[13,14]$. Primary paper mill sludge (PS), a residue derived from the primary treatment of the effluents of the pulp and paper industry, may be a promising precursor of ACs. Its potential as precursor of non-ACs, applied in the removal of pharmaceuticals from water, has already been shown [15-20]. Pulp and paper industry generates a huge amount of residues $[20,21]$ and this application represents an unconventional and innovative way of waste management [20], also contributing to minimize the high costs associated to the application of ACs in WWTPs.

The production of $\mathrm{AC}$ can be performed via physical or chemical activation together with thermal decomposition under limited supply of oxygen (pyrolysis). The main advantages of chemical activation include the achievement of higher $S_{\mathrm{BET}}$ and lower production costs when compared with physical activation [22]. Moreover, chemical activation can be performed in one step, involving the impregnation of the raw material with the activating agent followed by the pyrolysis of the impregnated material, with the advantage of being costless relatively to the two-step activation. The most commonly used activating agents are zinc chloride $\left(\mathrm{ZnCl}_{2}\right)$, alkali hydroxides, generally, potassium hydroxide $(\mathrm{KOH})$ and sodium hydroxide $(\mathrm{NaOH})$, phosphoric acid $\left(\mathrm{H}_{3} \mathrm{PO}_{4}\right)$, sulphuric acid $\left(\mathrm{H}_{2} \mathrm{SO}_{4}\right)$, and potassium carbonate $\left(\mathrm{K}_{2} \mathrm{CO}_{3}\right)[23] . \mathrm{KOH}$ and $\mathrm{K}_{2} \mathrm{CO}_{3}$ are believed to act as intercalating agents with potassium ions functioning as template for the formation of porosity [24]. These two activating agents present themselves as more environmentally friendly when compared with the use of acids or even $\mathrm{ZnCl}_{2}$. 
The remediation of contaminated water and the industrial waste management are two great challenges of the scientific community that could be addressed in an integrated approach. Therefore, in this work, a full factorial design was applied for the production of an alternative AC using PS as precursor with the aim of obtaining a waste-based highly efficient material, capable of competing with commercial AC (often produced from nonrenewable sources). Pyrolysis temperature, residence time, activating agent and precursor/activating agent ratio were tested and the responses analysed were the yield of production, percentage of adsorption of three different classes of pharmaceuticals - an antiepileptic (carbamazepine, CBZ), an antibiotic (sulfamethoxazole, SMX), and an antidepressant (paroxetine, PAR) -, $S_{\mathrm{BET}}$, and total organic carbon (TOC). A commercial $\mathrm{AC}$ was used as reference.

\section{Experimental}

\subsection{Reagents}

The reagents used for the activation process were potassium hydroxide $(\mathrm{KOH}$; EKA PELLETS, $\geq 86 \%)$ and potassium carbonate $\left(\mathrm{K}_{2} \mathrm{CO}_{3}\right.$; AnalaR NORMAPUR, $\left.99.8 \%\right)$. For the washing step hydrochloric acid ( $\mathrm{HCl}$; AnalaR NORMAPUR, 37\%) was used. The pharmaceuticals used for the adsorption tests were CBZ (Sigma-Aldrich, 99\%); SMX (TCI, $>98 \%$ ); and PAR (paroxetine-hydrochloride; TCI, >98\%). All the solutions were prepared in ultra-pure water obtained from a Milli-Q Millipore system (Milli-Q plus 185). The AC used as reference was PBFG4, kindly provided by Chemviron. 


\subsection{Preparation of ACs - Full Factorial Design and statistical analysis}

To produce the ACs, PS from a pulp and paper industry was used as precursor. The factory operates with a kraft elemental chlorine free production process and uses eucalyptus wood (Eucalyptus globulus). PS was dried at room temperature followed by a $24 \mathrm{~h}$ period at $105^{\circ} \mathrm{C}$ in an oven and then it was grinded with a blade mill.

ACs were prepared by chemical activation, using $\mathrm{KOH}$ or $\mathrm{K}_{2} \mathrm{CO}_{3}$, and pyrolysis performed in one step to minimize the costs associated with the production. To test the best production conditions, a full factorial design was applied using four factors at two levels, namely, the pyrolysis temperature $\left(650^{\circ} \mathrm{C}\right.$ and $\left.800{ }^{\circ} \mathrm{C}\right), \mathrm{X}_{1}$, the residence time $(60$ minutes and 150 minutes), $X_{2}$, the precursor/activating agent ratio (10:1 and 1:1), $X_{3}$, and the type of activating agent $\left(\mathrm{K}_{2} \mathrm{CO}_{3}\right.$ and $\left.\mathrm{KOH}\right), \mathrm{X}_{4}$. PS was impregnated with the activating agent, stirred during $1 \mathrm{~h}$, and left to dry at room temperature. The dried materials were pyrolysed, under $\mathrm{N}_{2}$ atmosphere, in porcelain crucibles in a muffle (Nüve, series MF 106, Turkey). Overall, sixteen ACs were obtained (ACs 1 to 16), which were subjected to a washing step with a $1.2 \mathrm{M}$ solution of $\mathrm{HCl}$ to remove ashes. The responses considered to perform the statistical analysis were the yield of production $(\eta)$, calculated by equation 1 , the percentage of adsorption for CBZ, SMX, and PAR, the $S_{\mathrm{BET}}$, and the TOC.

$$
\eta(\%)=\frac{\text { final mass of } A C(g)}{\text { mass of percursor }(g)} \times 100 \%
$$

The behaviour of the responses was described by a second-order interaction model (equation 2),

$$
y=\beta_{0}+\sum_{i=1}^{k} \beta_{i} x_{i}+\sum_{1 \leq i \leq j}^{k} \beta_{i j} x_{i} x_{j}+\varepsilon
$$

where $k$ is the number of variables, $\beta_{0}$ is a constant, $\beta_{i}$ is the coefficient of the effect of the variable $x_{i}$, the constant $\beta_{i j}$ represents the coefficients of the interaction 
parameters, $x_{i}$ and $x_{j}$ are the variables, and $\varepsilon$ is the random error term [25]. The significant factors influencing each response were determined by means of the normal probability distribution plots. The effects outside the normal distribution were those considered for the model, since their estimates are the ones that most influence the responses. Then, the regression models were obtained by the least squares method and statistically evaluated by an analysis of variance (ANOVA) (Table S1 of Supplementary Material (SM)). This statistical analysis allowed to determine the best operational conditions for each response.

A principal component analysis (PCA) was applied to group the produced ACs and to observe how they distributed themselves according to the responses. Also, a multiple response analysis was applied to determine the set of conditions that simultaneously satisfied all responses, corresponding to the best balance among different response variables. This was achieved by applying a Derringer function, also called desirability function (equations S1 and S2 in SM). The $Y_{i^{*}}$ and $Y_{i}^{*}$ (equation S1) used were, respectively, the minimum and maximum values obtained for each response, and the $r$ value considered was 1, indicating that all responses possess the same importance [26]. OCTAVE was used to perform the statistical analysis for ANOVA, PCA and desirability function.

\subsection{Adsorption tests (batch experiments)}

Batch experiments under agitation were carried out to determine the adsorption of the selected pharmaceuticals onto the sixteen produced ACs and to evaluate their adsorptive performance. Pharmaceutical solutions of CBZ, SMX, or PAR with an initial concentration of $5 \mathrm{mg} \mathrm{L}^{-1}$ were prepared separately. Each pharmaceutical solution was placed in contact 
with each of the 16 ACs and shaken overnight in an overhead shaker (Heidolph, Reax 2) at $80 \mathrm{rpm}$ under controlled temperature $\left(25.0 \pm 0.1{ }^{\circ} \mathrm{C}\right)$. The concentration of ACs was $0.015 \mathrm{~g} \mathrm{~L}^{-1}$ which was chosen accordingly to the results obtained in preliminary tests. The solutions were filtered through $0.22 \mu \mathrm{m}$ PVDF filters (Whatman) and immediately analysed. The quantification of pharmaceuticals in the aqueous phase was carried out by UV-Vis (T90+ UV/Vis Spectrometer) at $214 \mathrm{~nm}$ for CBZ and at $200 \mathrm{~nm}$ for SMX and PAR. The calibration curves were applied to a concentration range between 0.5 and $5 \mathrm{mg} \mathrm{L}^{-1}$. All the matrices of the ACs were analysed and used as reference solution in the absorbance measurements. The adsorption tests were also performed for the commercial AC, PBFG4, used for comparison. All experiments were performed in triplicate. Also, control experiments (pharmaceutical solution without the adsorbent) were carried out simultaneously with adsorption experiments and used as reference for the calculation of adsorption percentages.

\subsection{Physical and chemical characterization of the ACs}

For all the produced and reference ACs, $S_{\mathrm{BET}}$ and TOC content were determined. Four ACs were selected, based on their high ability to remove the studied pharmaceuticals from water, and were further characterized by the point of zero charge $\left(\mathrm{pH}_{p z c}\right)$, the amount of surface acidic and basic functional groups, proximate and ultimate analyses and scanning electron microscopy (SEM), as described below.

The $S_{\mathrm{BET}}$ and micropore volume $\left(W_{0}\right)$ were determined by nitrogen adsorption isotherms. These isotherms were acquired at $77 \mathrm{~K}$ using a Micromeritics Instrument, Gemini VII 2380 after outgassing the materials overnight at $120^{\circ} \mathrm{C} . S_{\mathrm{BET}}$ was calculated 
from the Brunauer-Emmett-Teller equation [27] in the relative pressure range 0.01-0.1. Pore volume $\left(V_{\mathrm{p}}\right)$ was estimated from the amount of nitrogen adsorbed at a relative pressure of $0.99 . W_{0}$ was determined by applying the Dubinin-Astakhov (DA) equation to the lower relative pressure zone of the nitrogen adsorption isotherm.

TOC was calculated by difference between the total carbon (TC) and inorganic carbon (IC) contents, that were determined through a TOC analyzer (TOC-VCPH Shimadzu, solid sample module SSM-5000A). All the analyses were performed in triplicate.

$\mathrm{pH}_{p z c}$ was determined by the $\mathrm{pH}$ drift method described in Jaria et al. (2015) [17]. For the determination of the main surface functional groups of the ACs, the Boehm's titration method was used, as described in Ferreira et. al (2016) [18]. Briefly, $35 \mathrm{~mL}$ of the bases $\mathrm{NaOH}, \mathrm{Na}_{2} \mathrm{CO}_{3}$ and $\mathrm{NaHCO}_{3} 0.05 \mathrm{M}$, and acid, $\mathrm{HCl} 0.05 \mathrm{M}$, were separately equilibrated with $350 \mathrm{mg}$ of $\mathrm{AC}$ and stirred at $80 \mathrm{rpm}$ during $24 \mathrm{~h}$ at $25^{\circ} \mathrm{C}$. Then, the solutions were filtered through $0.22 \mu \mathrm{m}$ PVDF filters and $20 \mathrm{~mL}$ of each filtrate was titrated with standardized solutions of $\mathrm{HCl}$, in the case of the reactive bases, and $\mathrm{NaOH}$ in the case of $\mathrm{HCl}$, to determine the quantity of the respective reactants that were neutralized during the initial equilibration.

Proximate analysis was performed by thermogravimetric analysis (TGA) in a thermogravimetric balance Setsys Evolution 1750, Setaram, TGA mode (S type sensor). Standard methods to determine the moisture (UNE 32002) (AENOR, 1995), volatile matter (UNE 32019) (AENOR, 1985) and ash content (UNE 32004) (AENOR, 1984) were employed and described in Jaria et al. (2017) [20].

Ultimate analysis was performed in a LECO CHNS-932 elemental analyser. Standard methods were employed to determine $\mathrm{C}, \mathrm{H}, \mathrm{N}$ [28] and S [29]. The percentage of oxygen 
was calculated by difference between $100 \%$ and the total percentage of $\mathrm{C}, \mathrm{H}, \mathrm{N}$ and $\mathrm{S}$, after correcting for moisture. Sample amounts used in each analysis ranged between 1 and $2 \mathrm{mg}$. The carrier gas used was helium $\left(200 \mathrm{~mL} \mathrm{~min}^{-1}\right)$ and the samples were subjected to combustion $975^{\circ} \mathrm{C}$ using $15 \mathrm{~mL}$ of oxygen. Sulfamethazine was used as standard.

The surface morphology of the produced ACs was analysed by SEM using a Hitachi SU-70. The images were obtained at magnifications of 3000, 10000,30000 , and 50000 times.

\section{Results and Discussion}

\subsection{Full factorial design: responses}

The design matrix (codified variables) and the response values for the yield, percentage of adsorption (SMX, CBZ, and PAR), TOC and $S_{\mathrm{BET}}$ are presented in Table 1. Also, the cumulative percentage of adsorption of the three pharmaceuticals and the $S_{\mathrm{BET}}$ of the ACs are graphically represented in Figure 1.

The results indicate that the highest temperature $\left(\mathrm{X}_{1}\right)$ and the highest impregnation ratio $\left(\mathrm{X}_{3}\right)$ were the most favourable conditions. The ACs from AC1 to AC8 simultaneously present the largest percentages of adsorption and highest $S_{\mathrm{BET}}$. These ACs have in common being produced with the maximum pyrolysis temperature here considered $\left(800^{\circ} \mathrm{C}\right)$, showing that this temperature positively influences the development of porosity. ACs 3,4 , 6, and 7 present the highest $S_{\mathrm{BET}}$ and the largest percentages of adsorption for CBZ, SMX and PAR. It is noteworthy that these waste-based ACs removed significantly higher pharmaceutical percentages than the commercial AC (PBFG4) used as reference. Considering the results of TOC, all the produced carbons possess a high TOC content. Despite not being considered as a response of the full factorial design, it is also interesting 
to refer that all ACs present very low percentage of IC (below 2\%). Amongst the 16 experiments, ACs 3, 4, 6, and 7 present the highest TOC contents, which are very close to the TOC of the commercial AC.

\subsection{Full factorial design: model fitting and statistical analysis}

The normal probability distribution plots of the factors influencing each response are depicted in Figures S1 to S6 (SM). The regression models (equations 3 to 8) were statistically evaluated as presented in Table S2 (SM). The $P$-value for all models is less than 0.05 , indicating that the models satisfactorily fit the experimental data.

$\hat{Y}_{\text {yield }}=15.28-1.38 x_{2}-10.50 x_{3}-1.77 x_{1} x_{3}$

$\hat{Y}_{S M X}=32.47+16.89 x_{1}+14.09 x_{3}+10.70 x_{1} x_{3}$

$\hat{Y}_{C B Z}=31.11+24.46 x_{1}+11.17 x_{3}+9.45 x_{1} x_{3}$

$\hat{Y}_{P A R}=39.07+29.06 x_{1}+7.75 x_{3}+5.36 x_{1} x_{3}$

$\hat{Y}_{T O C}=55.05-1.25 x_{1}+4.12 x_{3}+5.78 x_{1} x_{3}$

$\hat{Y}_{B E T}=795.76+371.44 x_{1}+262.40 x_{3}-25.83 x_{2} x_{3} x_{4}$

The results on the optimization of the experimental data, performed using a surface response methodology, are presented in Table 2 . The surfaces concerning the dependence of the response in terms of the residence time $\left(\mathrm{X}_{2}\right)$ versus the temperature of pyrolysis $\left(\mathrm{X}_{1}\right)$; precursor/activating agent ratio $\left(\mathrm{X}_{3}\right)$ versus the temperature of pyrolysis $\left(\mathrm{X}_{1}\right)$; and/or precursor/activating agent ratio $\left(\mathrm{X}_{3}\right)$ versus the residence time $\left(\mathrm{X}_{2}\right)$ are presented in Figures $\mathrm{S} 7$ to S12, in SM. 
Overall, factors $\mathrm{X}_{1}$ and $\mathrm{X}_{3}$ have the highest influence, presenting better results for the higher level, corresponding to $800{ }^{\circ} \mathrm{C}$ and $1: 1$ ratio of precursor/activating agent, respectively (Table 2). The type of activating agent showed to have little influence in the values of $S_{\mathrm{BET}}$. An important aspect of this study is that the chemical activation was performed at a precursor/activating agent ratio of 1:1 when specially, in the case of $\mathrm{KOH}$, the chemical activation usually uses a precursor/ $\mathrm{KOH}$ ratio between 2 and 4 [30-32]. Also, it is important to highlight that the heat treatment (pyrolysis) and activation were performed in one step only, reducing the environmental impact of the production and also the production costs. The PCA biplot analysis (Figure 2) clearly shows that the ACs 3, 4, 6, and 7 are grouped, with very similar responses in what concerns $S_{\mathrm{BET}}$ and percentage of adsorption for SMX, CBZ, and PAR. This group is separated from the other produced carbons by the TOC and is clearly more distant from the yield of production, which is confirmed by the low yield values that ACs 3, 4, 6 and 7 presented. This group presents the highest $S_{\mathrm{BET}}$ and adsorption percentages, and therefore, these materials were chosen to perform further physicochemical characterization, which is presented in section 3.3.

Concerning the application of the desirability function to analyse the optimization of all responses simultaneously, the results show that the AC with the best responses was the one produced with a temperature of pyrolysis of $800{ }^{\circ} \mathrm{C}$, a residence time of 60 minutes, a precursor/activating agent ratio close to $1: 1$ ( 0.6 in the codified variables between -1 and 1, meaning a precursor/activating agent ratio around 2:1 to $3: 1$ ), and using $\mathrm{KOH}$ as activating agent. This production conditions are closer to those used to prepare AC 4, which is consistent with the optimization results (Table 2). The desirability value, $D$, was 0.643 , indicating a favourable balance of the responses. 


\subsection{Physical and chemical characterisation of the selected ACs}

All the produced ACs were analysed through TOC and $S_{\text {BET }}$ analyses. The ACs 3, 4, 6 and 7, indicated by the PCA as the carbons with the highest $S_{\mathrm{BET}}$ and adsorption percentage towards the three studied pharmaceuticals, were selected for further physical and chemical characterisation to deepen the knowledge on their properties, namely in what concerns their surface chemistry. These characteristics are also important for the future analysis of the interactions between the adsorbents and the adsorbates.

\subsubsection{Proximate and Ultimate Analyses}

The results of proximate and ultimate analyses (Table 3) show that the carbon materials possess a high content in fixed carbon, which is consistent with the TOC determination (Table 1). Correspondingly, these ACs possess low content in ashes (below $15 \%$ ) which is also in accordance with the low IC content of the samples.

It is well known that ACs contain several heteroatoms, being hydrogen, oxygen, nitrogen, and sulphur, the most abundant. All the heteroatoms are important to the properties of the ACs, but oxygen-containing functional groups, namely the ones at the edge of the structure, are those that have greatest influence in the surface chemistry of the materials [33]. The four best ACs possess a high content in oxygen and the high $\mathrm{O} / \mathrm{C}$ atomic ratio indicates the high incidence of oxygenated functional groups such as hydroxyl, carboxylate, and carbonyl. The low values of $\mathrm{H} / \mathrm{C}$ atomic ratios indicate a high degree of aromaticity of the ACs [12], relatively to the raw material (PS). 


\subsection{2. $\mathrm{pH}_{p z c}$ and surface chemical groups}

The results obtained for $\mathrm{pH}_{p z c}$ and surface functionality of the four best adsorbents produced are presented in Figure 3 and in Table S3 of SM.

Regarding the acidity/basicity, the $\mathrm{pH}_{p z c}$ clearly indicates that the selected ACs present an acidic surface which is confirmed by the determination of the acidic oxygencontaining functional groups by the Boehm's titrations (Figure 3 and Table S3 of SM). Besides the acidic groups (carboxyl, lactones, and phenols), the Boehm's titration also allows to determine the total amount of basic groups. From the results, it is possible to see that the surface chemistry of the ACs 3, 4, 6 and 7 are mostly determined by phenols and lactones. These are mainly oxygenated groups, which is in agreement with the high $\mathrm{O} / \mathrm{C}$ atomic ratio presented in Table 3.

Some values obtained for carboxylic groups, namely for ACs 4 and 7, are negative which cannot be considered as valid results. These negative values can be explained by the inexistence or very low amounts of carboxyl groups, associated with some sources of ambiguity in the results of this methodology which have already been pointed out by several authors: a) simple titration ratios are not always attained on the uptake of bases, b) the bases uptake can be affected by the equilibration time in a porous carbon c) it can occur restriction on the accessibility of the bases to inner pores and d) it may exist side reactions on the carbon surface or with the reactants [30]. Furthermore, the stereochemical proximity between functional groups can alter the properties of each one, since it is known that the properties of the functional groups are strongly related to their local environment $[30,33]$. One can also observe that AC 7 possesses less lactones than the other three ACs. Also, AC 4 is the one that possesses the highest content of total basic groups combined with a low content of total acidic groups, which is in accordance with the $\mathrm{pH}_{p z c}$ as it is the carbon with 
the highest $\mathrm{pH}_{p z c}$ (when compared with $\mathrm{ACs} 3,6$ and 7). This is clearly seen in the graphs a) and $\mathrm{b}$ ) in Figure 3 where it is interesting to observe that the $\mathrm{pH}_{p z c}$ shows the same pattern (dotted lines) than the content of basic groups although not so pronounced. AC 6 possesses a slightly higher amount of acidic groups which is also in accordance with the $\mathrm{pH}_{p z c}$ values.

\subsection{3. $S_{B E T}$}

The results concerning the $\mathrm{N}_{2}$ adsorption isotherms for ACs 3, 4, 6, and 7 (Table 1 and 4) show, as expected, that the four ACs with higher $S_{\text {BET }}$ present a high prevalence of micropores (around $68 \%$ of the total pore volume). Also, the apparent densities are very low which is consistent with the high degree of microporosity of the materials and also with low yields of production obtained for these materials.

\subsubsection{SEM}

SEM was used to analyse the surface morphology of ACs 3, 4, 6 and 7. From the SEM images (Figure 4), it can be observed that the produced ACs possess a high level of porosity. The structure is irregular and the presence of pores is well defined, as it was expected according to the results obtained by the $\mathrm{N}_{2}$ adsorption isotherms (Table 4). However, the amplification used in SEM mostly revealed the macroporosity ( $>50 \mathrm{~nm}$ ) of the ACs, not being able to detect microporosity (Figure 4).

\subsection{Future work}

The potential demonstrated by the ACs produced (particularly ACs 3, 4, 6 and 7) justify an additional evaluation of their performance, including kinetic and equilibrium studies and the evaluation of their adsorptive capacity in wastewater. Also, in order to 
assess the real applicability of using PS as an AC precursor, an inclusive economic analysis should be the focus of future work. Some relevant aspects are to be considered, namely the impact of the pyrolysis energy balance (energy demand versus energy recovery), costs of activating and washing reagents, use of a waste as raw material (taking into account savings in waste management and in the exploitation of conventional AC precursors) and scale of the production facilities.

\section{Conclusions}

In this work, a full factorial design was applied to produce a waste-based $\mathrm{AC}$ with optimal conditions to remove three pharmaceuticals from water. Four factors (pyrolysis temperature, residence time, precursor/activating agent ratio, and type of activating agent) were studied at two levels and their influence in six responses (yield of production, percentage of adsorption for SMX, CBZ, and PAR, TOC, and $\mathrm{S}_{\mathrm{BET}}$ ) were evaluated. The main factors affecting the $S_{\mathrm{BET}}$ and the percentage of adsorption of the selected pharmaceuticals, were found to be the pyrolysis temperature and the precursor/activating agent ratio. The highest temperature $\left(800^{\circ} \mathrm{C}\right)$ and highest precursor/activating agent ratio (1:1) resulted in $S_{\mathrm{BET}}$ between 1380 and $1630 \mathrm{~m}^{2} \mathrm{~g}^{-1}$ and percentages of adsorption for the three pharmaceuticals of $78 \%$ (in average), using only $0.015 \mathrm{mg} \mathrm{L}^{-1}$ of AC. A desirability function allowed to make a multivariate analysis of all the responses and to select the best produced AC. Overall, the results obtained show that the AC produced according to the optimal selected conditions are suitable for the removal of CBZ, SMX and PAR from water, with adsorption percentages significantly higher than those of a reference commercial AC. Thus, using primary paper mill sludge as precursor, the full factorial 
design was proven to be an effective approach for selecting the most appropriate conditions to produce a highly efficient AC capable to compete with commercial ACs in the market.

\section{Acknowledgments}

This work was funded by FEDER through COMPETE 2020 and by national funds through FCT by the research project PTDC/AAG-TEC/1762/2014. Thanks are also due for the financial support to CESAM (UID/AMB/50017-POCI-01-0145-FEDER-007638), to FCT/MCTES through national funds (PIDDAC), and the co-funding by the FEDER, within the PT2020 Partnership Agreement and Compete 2020. The work was also developed within the scope of the project CICECO - Aveiro Institute of Materials, POCI-01-0145FEDER-007679 (UID/CTM/50011/2013), financed by national funds through the FCT/MEC. Vânia Calisto also thanks FCT for her postdoctoral grant (SFRH/BPD/78645/2011). Marta Otero and Sérgio Santos thank support by the FCT Investigator Program (IF/00314/2015 and IF/00973/2014, respectively).

\section{References}

[1] K. Jagiello, A. Mostrag-Szlichtyng, A. Gajewicz, T. Kawai, Y. Imaizumi, T. Sakurai, H. Yamamoto, N. Tatarazako, K. Mizukawa, Y. Aoki, N. Suzuki, H. Watanabe, T. Puzyn, Towards modelling of the environmental fate of pharmaceuticals using the QSPR-MM scheme, Environmental Modelling \& Software, 72 (2015) 147-154.

[2] R. Gurke, M. Rossler, C. Marx, S. Diamond, S. Schubert, R. Oertel, J. Fauler, Occurrence and removal of frequently prescribed pharmaceuticals and corresponding metabolites in wastewater of a sewage treatment plant, Science of the Total Environment, 532 (2015) 762-770.

[3] V. Calisto, V.I. Esteves, Psychiatric pharmaceuticals in the environment, Chemosphere, 77 (2009) 1257-1274. 
[4] A. Jelic, M. Gros, A. Ginebreda, R. Cespedes-Sánchez, F. Ventura, M. Petrovic, D. Barcelo, Occurrence, partition and removal of pharmaceuticals in sewage water and sludge during wastewater treatment, Water Research, 45 (2011) 1165-1176.

[5] C.A. Kinney, E.T. Furlong, S.L. Werner, J.D. Cahill, Presence and distribution of wastewater-derived pharmaceuticals in soil irrigated with reclaimed water, Environmental Toxicology and Chemistry, 25 (2006) 317-326.

[6] Y. Luo, W. Guo, H.H. Ngo, L.D. Nghiem, F.I. Hai, J. Zhang, S. Liang, X.C. Wang, A review on the occurrence of micropollutants in the aquatic environment and their fate and removal during wastewater treatment, Science of the Total Environment, 473-474 (2014) 619-641.

[7] J. Rivera-Utrilla, M. Sanchez-Polo, M.A. Ferro-Garcia, G. Prados-Joya, R. OcampoPerez, Pharmaceuticals as emerging contaminants and their removal from water. A review, Chemosphere, 93 (2013) 1268-1287.

[8] European Parliament, Directive 2013/39/EU of the European Parliament and of the Council of $12^{\text {th }}$ August 2013 amending Directives 2000/60/EC and 2008/105/EC as regards priority substances in the field of water policy, Official Journal of the European Union, (2013).

[9] V. Calisto, C.I.A. Ferreira, S.M. Santos, M.V. Gil, M. Otero, V.I. Esteves, Production of adsorbents by pyrolysis of paper mill sludge and application on the removal of citalopram from water, Bioresource Technology, 166 (2014) 335-344.

[10] S. Kushwaha, H. Soni, V. Ageetha, P. Padmaja, An Insight Into the Production, Characterization, and Mechanisms of Action of Low-Cost Adsorbents for Removal of Organics From Aqueous Solution, Critical Reviews in Environmental Science and Technology, 43 (2013) 443-549.

[11] A. Vona, F. di Martino, J. Garcia-Ivars, Y. Picó, J.-A. Mendoza-Roca, M.-I. IborraClar, Comparison of different removal techniques for selected pharmaceuticals, Journal of Water Process Engineering, 5 (2015) 48-57.

[12] M.B. Ahmed, J.L. Zhou, H.H. Ngo, W. Guo, Insight into biochar properties and its cost analysis, Biomass and Bioenergy, 84 (2016) 76-86.

[13] T. Maneerung, J. Liew, Y. Dai, S. Kawi, C. Chong, C.H. Wang, Activated carbon derived from carbon residue from biomass gasification and its application for dye 
adsorption: Kinetics, isotherms and thermodynamic studies, Bioresource Technology, 200 (2016) 350-359.

[14] Y. Li, X. Zhang, R. Yang, G. Li, C. Hu, Removal of dyes from aqueous solutions using activated carbon prepared from rice husk residue, Water Science \& Technology, 73 (2016) 1122-1128.

[15] V. Calisto, C.I.A. Ferreira, S.M. Santos, M.V. Gil, M. Otero, V.I. Esteves, Production of adsorbents by pyrolysis of paper mill sludge and application on the removal of citalopram from water, Bioresource Technology, 166 (2014) 335-344.

[16] V. Calisto, C.I.A. Ferreira, J.A. Oliveira, M. Otero, V.I. Esteves, Adsorptive removal of pharmaceuticals from water by commercial and waste-based carbons, Journal of Environmental Management, 152 (2015) 83-90.

[17] G. Jaria, V. Calisto, M.V. Gil, M. Otero, V.I. Esteves, Removal of fluoxetine from water by adsorbent materials produced from paper mill sludge, Journal of Colloid and Interface Science, 448 (2015) 32-40.

[18] C.I.A. Ferreira, V. Calisto, M. Otero, H. Nadais, V.I. Esteves, Comparative adsorption evaluation of biochars from paper mill sludge with commercial activated carbon for the removal of fish anaesthetics from water in Recirculating Aquaculture Systems, Aquacultural Engineering, 74 (2016) 76-83.

[19] R.N. Coimbra, V. Calisto, C.I.A. Ferreira, V.I. Esteves, M. Otero, Removal of pharmaceuticals from municipal wastewater by adsorption onto pyrolyzed pulp mill sludge, Arabian Journal of Chemistry, (2015), in press.

[20] G. Jaria, C.P. Silva, C.I.A. Ferreira, M. Otero, V. Calisto, Sludge from paper mill effluent treatment as raw material to produce carbon adsorbents: An alternative waste management strategy, Journal of Environmental Management, 188 (2017) 203-211.

[21] CELPA, Boletim Estatístico Indústria Papeleira Portuguesa. In $<$ http://www.celpa.pt/wp-content/uploads/2016/09/Boletim_WEB_2015.pdf>, (2015). [22] G.G. Stavropoulos, A.A. Zabaniotou, Minimizing activated carbons production cost, Fuel Processing Technology, 90 (2009) 952-957.

[23] G. Tzvetkov, S. Mihaylova, K. Stoitchkova, P. Tzvetkov, T. Spassov, Mechanochemical and chemical activation of lignocellulosic material to prepare powdered activated carbons for adsorption applications, Powder Technology, 299 (2016) 41-50. 
[24] H. Marsh, F. Rodríguez-Reinoso, Activated Carbon, First ed., Elsevier, England, 2006.

[25] M.A. Bezerra, R.E. Santelli, E.P. Oliveira, L.S. Villar, L.A. Escaleira, Response surface methodology (RSM) as a tool for optimization in analytical chemistry, Talanta, 76 (2008) 965-977.

[26] G. Derringer, R. Suich, Simultaneous Optimization of Several Response Variables, Journal of Quality Technology, 12 (1980) 214-219.

[27] S. Brunauer, P.H. Emmett, E. Teller, Adsorption of gases in multimolecular layers, Journal of the American Chemical Society, 60 (1938) 309-319.

[28] A.S.T.M. D5373-14, Standard Test Methods for Determination of Carbon, Hydrogen and Nitrogen in Analysis Samples of Coal and Carbon in Analysis Samples of Coal and Coke, ASTM, International, West Conshohocken, PA, 2014.

[29] A.S.T.M. D4239-14e1, Standard Test Method for Sulfur in the Analysis Sample of Coal and Coke Using High-Temperature Tube Furnace Combustion, ASTM, International, West Conshohocken, PA, 2014.

[30] T.J. Bandosz, Activated Carbon Surfaces in Environmental Remediation, First ed., Elsevier, New York, 2006.

[31] M.A. Lillo-Ródenas, J.P. Marco-Lozar, D. Cazorla-Amorós, A. Linares-Solano, Activated carbons prepared by pyrolysis of mixtures of carbon precursor/alkaline hydroxide, Journal of Analytical and Applied Pyrolysis, 80 (2007) 166-174.

[32] J. Alcañiz-Monge, M.J. Illan-Gomez, Insight into hydroxides-activated coals: chemical or physical activation?, Journal of Colloid and Interface Science, 318 (2008) 35-41.

[33] V.K. Thakur, M.K. Thakur, Chemical Functionalization of Carbon Nanomaterials: Chemistry and Applications, CRC Press, New York, 2015. 
Table 1 - Codified variables and responses obtained for the produced and the commercial ACs.

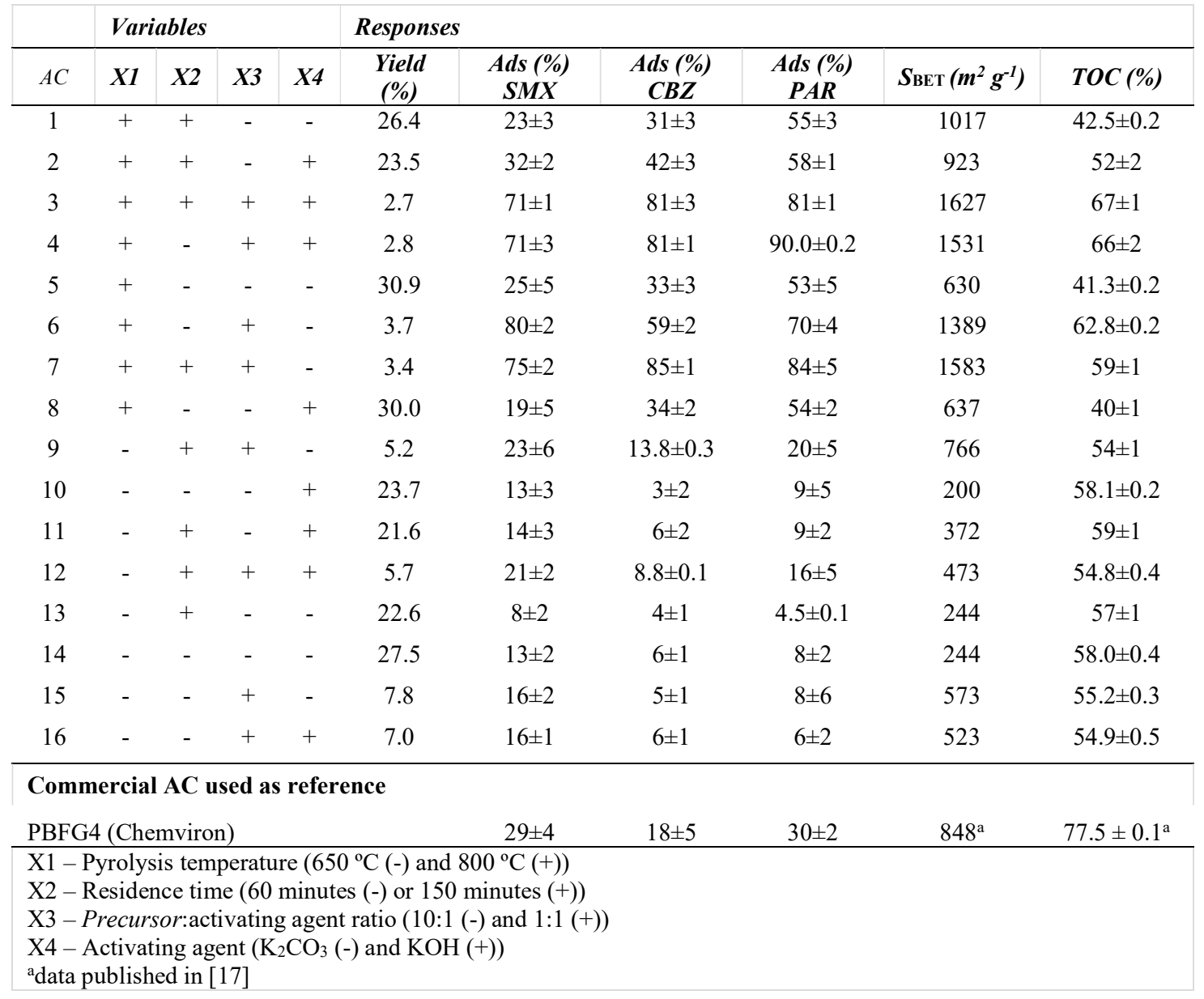

Table 2 - Optimization results for the experimental data with the maximum values obtained for each response.

\begin{tabular}{|c|c|c|c|c|c|c|}
\hline \multirow[b]{2}{*}{ Responses } & \multicolumn{6}{|c|}{ Optimization results } \\
\hline & Yield & Ads (\%) SMX & Ads (\%) CBZ & Ads (\%) PAR & TOC (\%) & $S_{\text {BET }}\left(m^{2} g^{-1}\right)$ \\
\hline Maximum & 28.93 & 74.16 & 76.19 & 81.24 & 63.69 & 1455 \\
\hline$X 1$ & $800^{\circ} \mathrm{C}$ & $800^{\circ} \mathrm{C}$ & $800^{\circ} \mathrm{C}$ & $800^{\circ} \mathrm{C}$ & $800^{\circ} \mathrm{C}$ & $800^{\circ} \mathrm{C}$ \\
\hline$X 2$ & $60 \mathrm{~min}$ & $*$ & $*$ & $*$ & $*$ & $60 \mathrm{~min}$ \\
\hline$X 3$ & $10: 1$ & $1: 1$ & $1: 1$ & $1: 1$ & $1: 1$ & $1: 1$ \\
\hline$X 4$ & $*$ & $*$ & $*$ & $*$ & $*$ & $\mathrm{KOH}$ \\
\hline
\end{tabular}

*Not significant 
Table 3 - Proximate and ultimate analyses of the raw material (PS) and ACs 3, 4, 6 and 7.

\begin{tabular}{|c|c|c|c|c|c|c|c|c|c|c|c|c|c|}
\hline \multirow{2}{*}{ 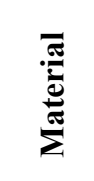 } & \multicolumn{5}{|c|}{ Proximate Analysis (db) } & \multicolumn{8}{|c|}{ Ultimate Analysis (dab) } \\
\hline & $\begin{array}{c}\text { Moisture } \\
(w t \%)\end{array}$ & $\begin{array}{c}\text { Volatile } \\
\text { Matter } \\
(w t \%)\end{array}$ & $\begin{array}{c}\text { Fixed } \\
\text { Carbon } \\
\text { Content }\end{array}$ & $\begin{array}{c}A s h \\
(w t \%)\end{array}$ & $F C / V M$ & $\% C$ & $\% H$ & $\% N$ & $\% S$ & $\% O$ & $O / C$ & $H / C$ & $C / N$ \\
\hline PS & 4.78 & 63.75 & 8.30 & 27.94 & 0.13 & 46.69 & 5.42 & 1.51 & 0.00 & 46.38 & 0.993 & 0.116 & 31.0 \\
\hline AC 3 & 6.85 & 23.26 & 63.12 & 13.62 & 2.71 & 72.27 & 1.35 & 0.69 & 0.38 & 25.31 & 0.350 & 0.019 & 105.1 \\
\hline AC 4 & 19.71 & 21.34 & 65.54 & 13.12 & 3.07 & 73.82 & 2.56 & 0.67 & 0.00 & 22.95 & 0.311 & 0.035 & 109.5 \\
\hline AC 6 & 16.38 & 25.46 & 62.57 & 11.97 & 2.46 & 81.32 & 1.48 & 0.87 & 0.00 & 16.33 & 0.201 & 0.018 & 93.2 \\
\hline AC 7 & 16.55 & 25.52 & 63.74 & 10.74 & 2.50 & 78.45 & 1.60 & 1.14 & 0.46 & 18.36 & 0.234 & 0.020 & 68.8 \\
\hline $\begin{array}{l}\text { Notes: } \\
\text { Except } \\
\text { The val } \\
\text { Ultimat } \\
\text { The val }\end{array}$ & $\begin{array}{l}\text { moisture, all } \\
\text { s of } \mathrm{FC} \text { were } \\
\text { analysis value } \\
\mathrm{s} \text { of } \% \mathrm{O} \text { wer }\end{array}$ & $\begin{array}{l}\text { values in } p \\
\text { etermined } \\
\text { are presen } \\
\text { estimated }\end{array}$ & $\begin{array}{l}\text { ximate ana } \\
\text { y difference } \\
\text { d in a dry a } \\
y \text { difference }\end{array}$ & ysis are $p$ & esented in & dry bas & $d b)$ & & & & & & \\
\hline
\end{tabular}

Table 4 - Textural parameters of the carbons: $V_{\mathrm{p}}$ - total pore volume; $W_{\mathrm{o}}$ - micropore volume; $L$-average micropore width for ACs 3, 4, 6 and 7 .

\begin{tabular}{ccccc}
\hline & & \multicolumn{3}{c}{$\mathbf{N}_{2}$ adsorption at $-\mathbf{1 9 6}^{\circ} \mathbf{C}$} \\
\cline { 3 - 5 } AC & $\begin{array}{c}\text { Apparent density } \\
\boldsymbol{\rho}_{\mathbf{H g}}\left(\mathbf{g ~ c m}^{-3}\right)\end{array}$ & $\boldsymbol{V}_{\mathbf{p}}\left(\mathbf{c m}^{\mathbf{3}} \mathbf{g}^{-1}\right)$ & \multicolumn{2}{c}{ Dubinin-Astakhov (DA) } \\
\cline { 3 - 5 } & 0.09 & 1.07 & 0.73 & $\boldsymbol{L}(\mathbf{n m})$ \\
\hline 3 & 0.10 & 0.96 & 0.69 & 1.74 \\
4 & 0.10 & 0.83 & 0.64 & 1.73 \\
6 & 0.09 & 1.00 & 0.71 & 1.66 \\
7 & & & & 1.74 \\
\hline
\end{tabular}


Figure $1-a)$ Percentage of adsorption of the three studied pharmaceuticals (CBZ, SMX, and PAR) and $b$ ) $S_{\mathrm{BET}}$ values, for the produced ACs and a commercial AC (PBFG4).

Figure 2 - Biplot of the principal component analysis.

Figure $3-a$ ) Plot of $\mathrm{pH}_{p z c}$ versus amount of total acidic surface groups for the ACs 3, 4, 6 and 7 ; b) Graphical representation of the amounts of the acidic and basic surface groups.

Figure 4 - SEM images at different magnifications (3 000x, $10000 x, 30000 x$, and 50 000x): a) AC 3; b) AC 4; c) AC 6; d) AC 7. 


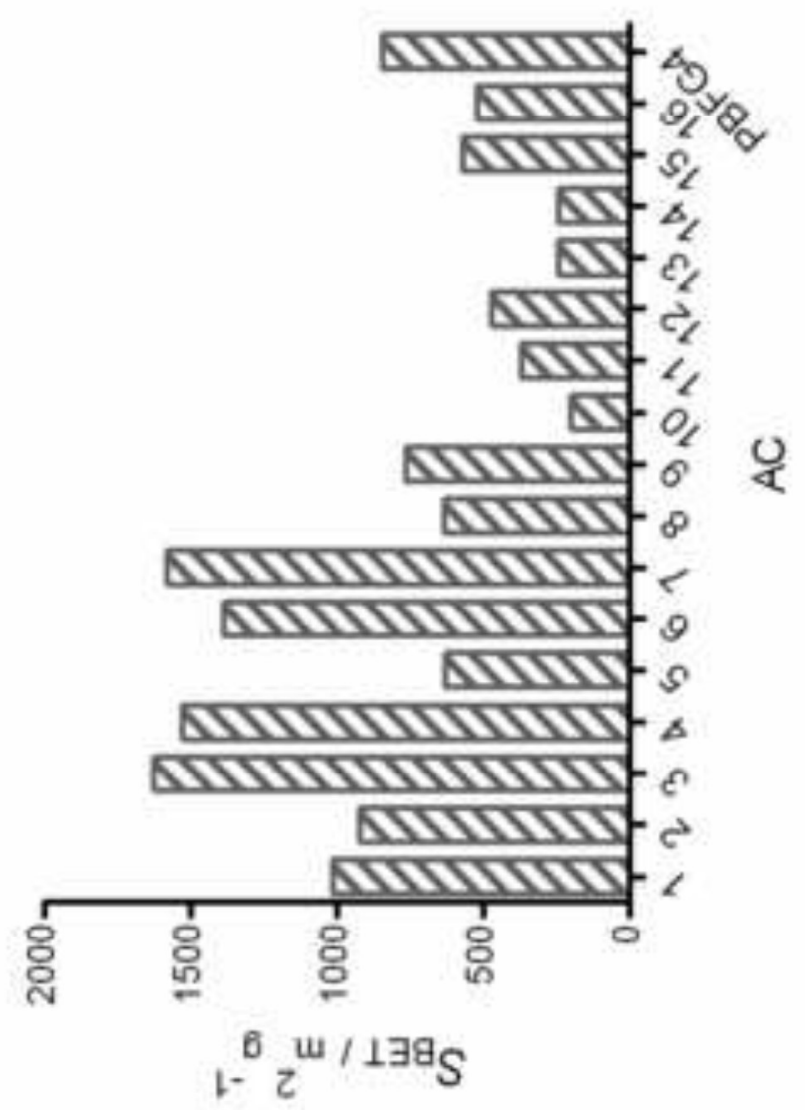

อ

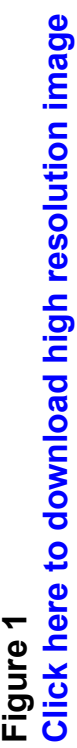

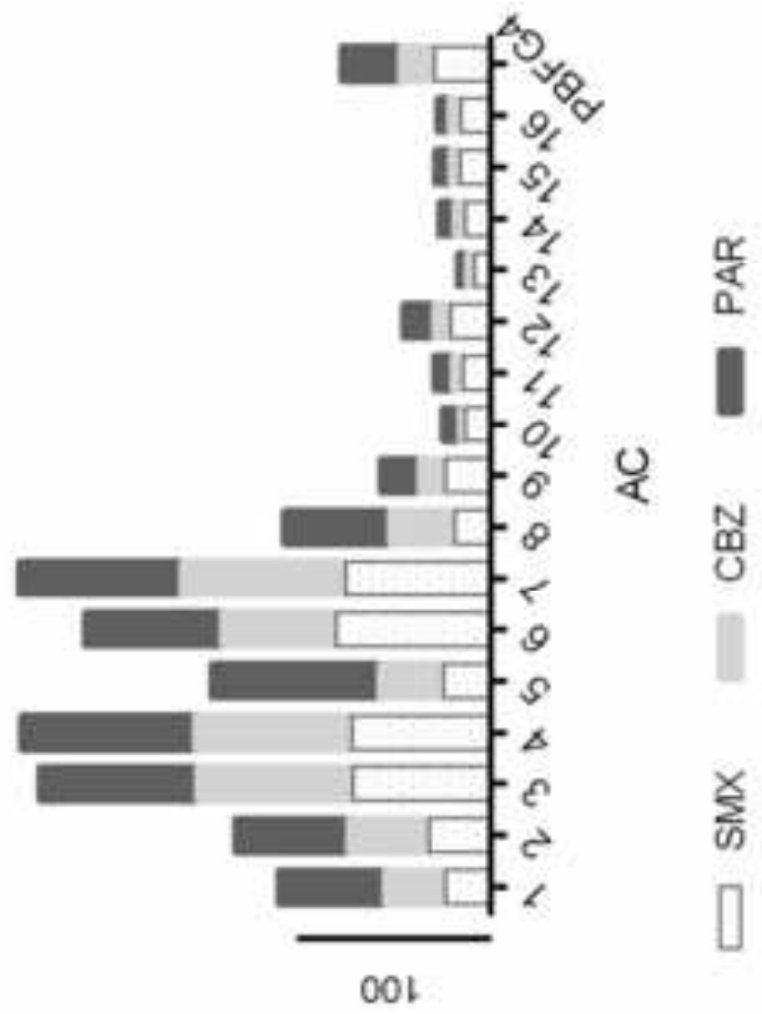

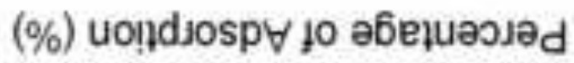

สิ 


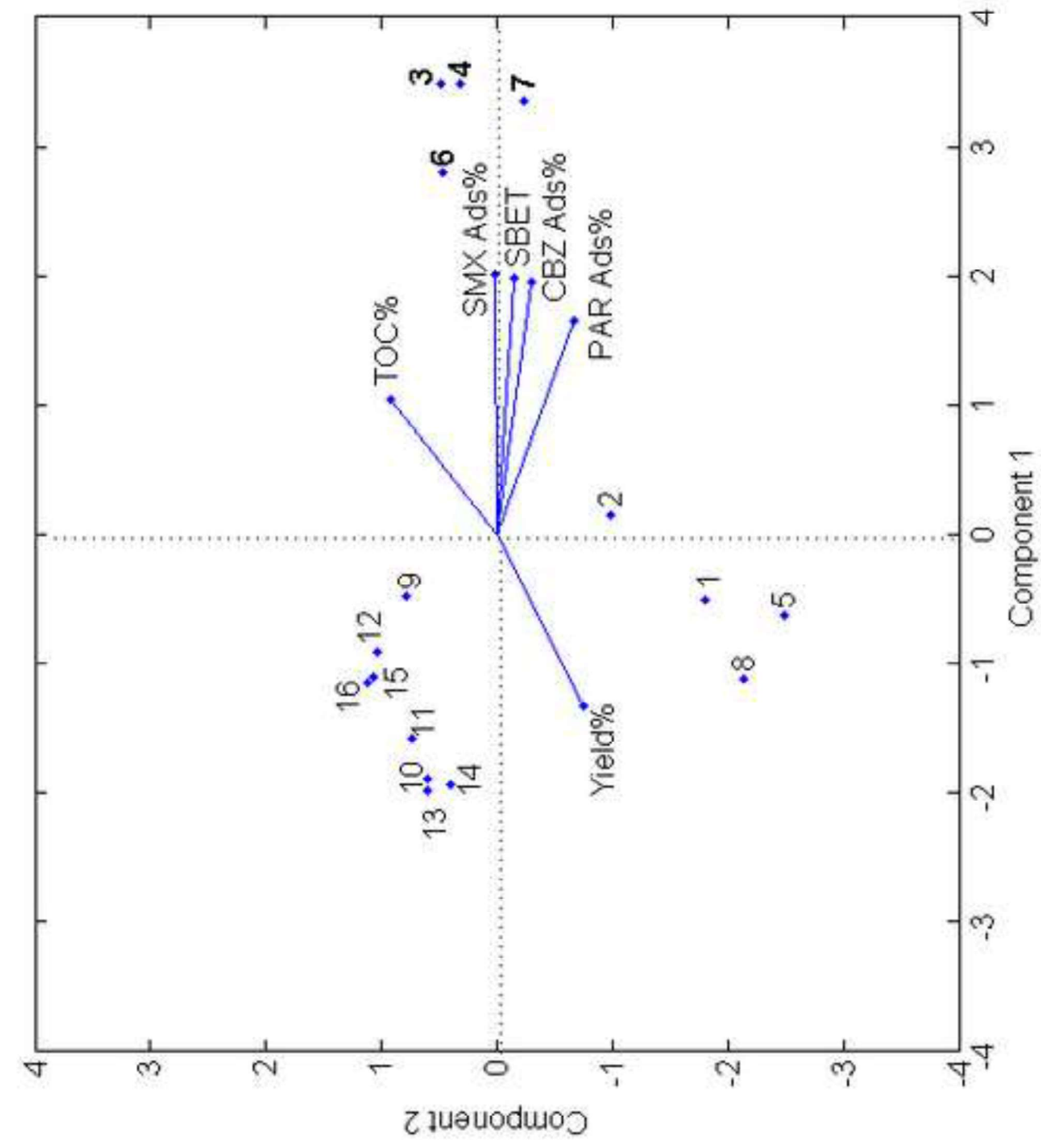




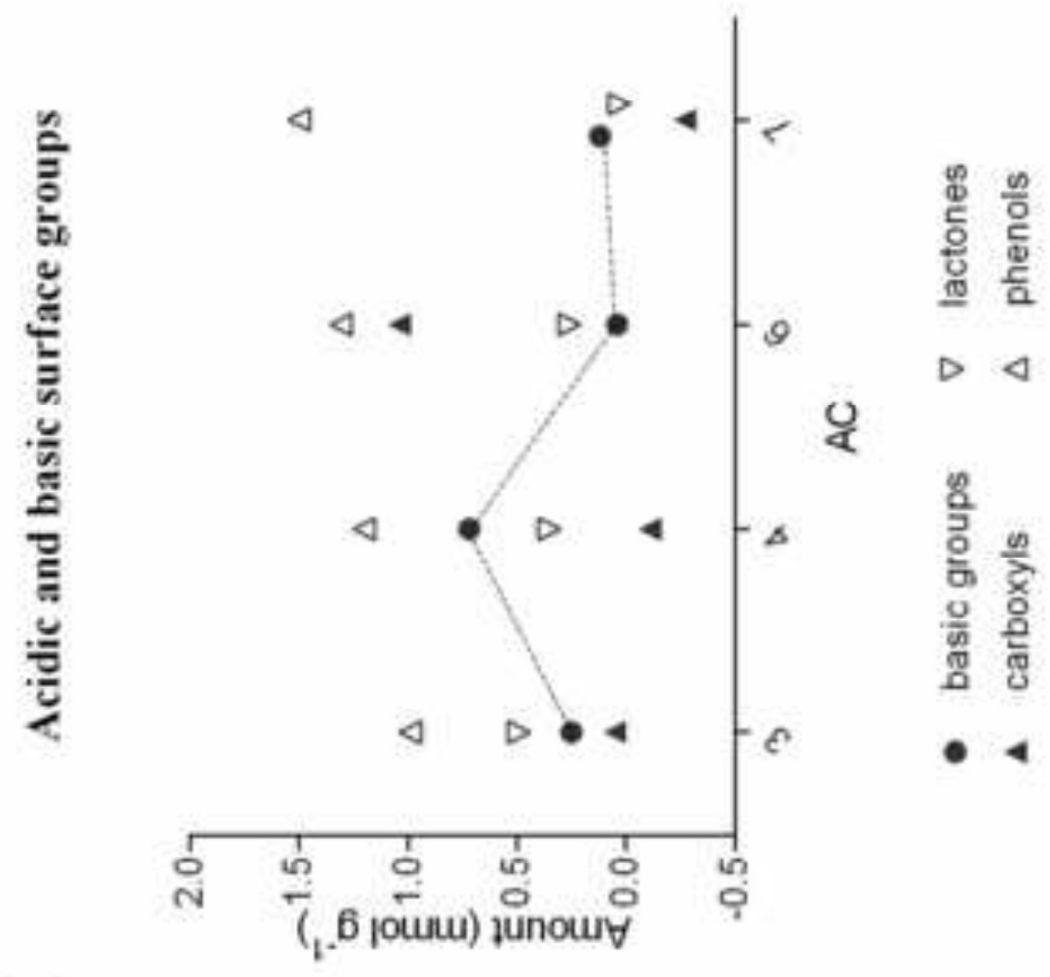

อิ

Amount of acidic groups ( $\mathrm{mmol} \mathrm{g}^{-1}$ )

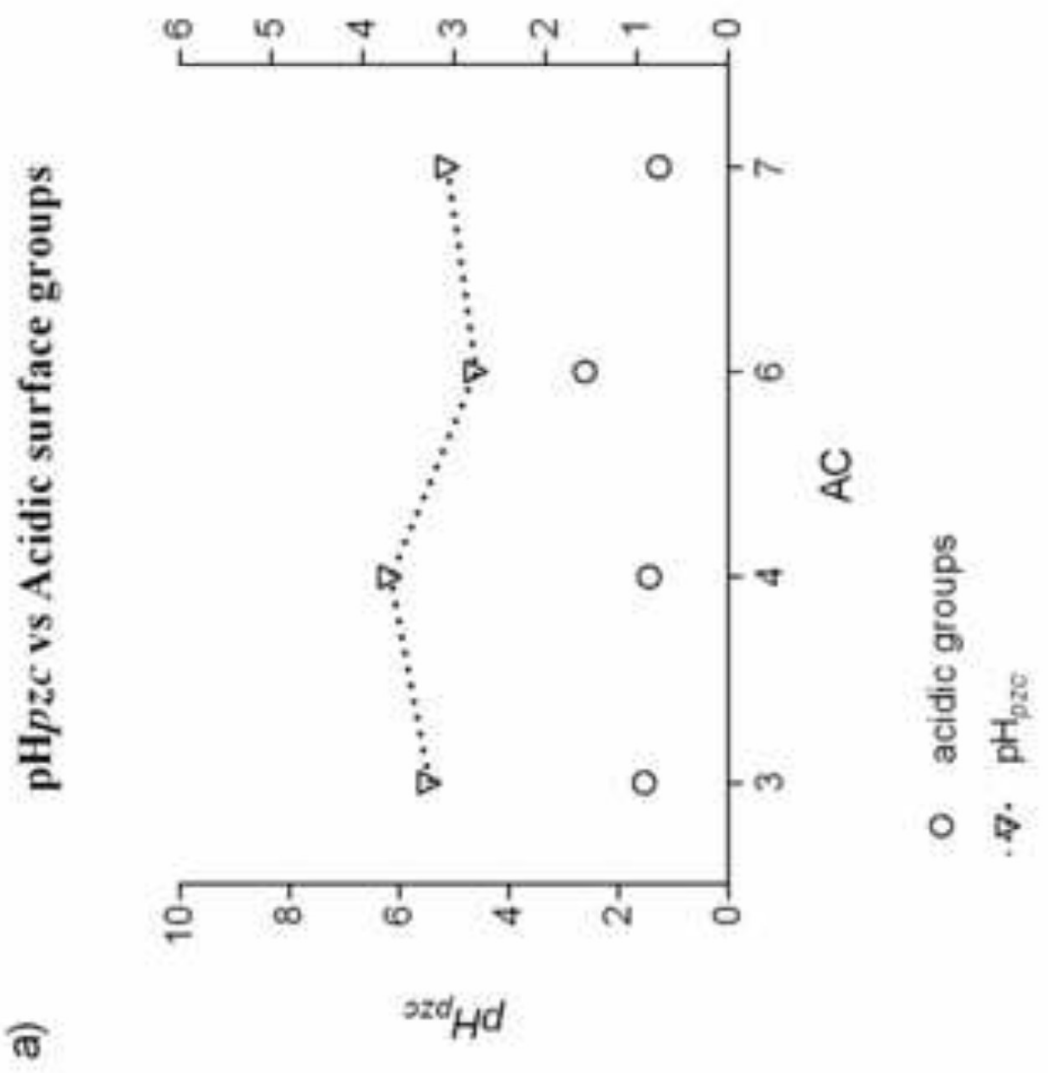



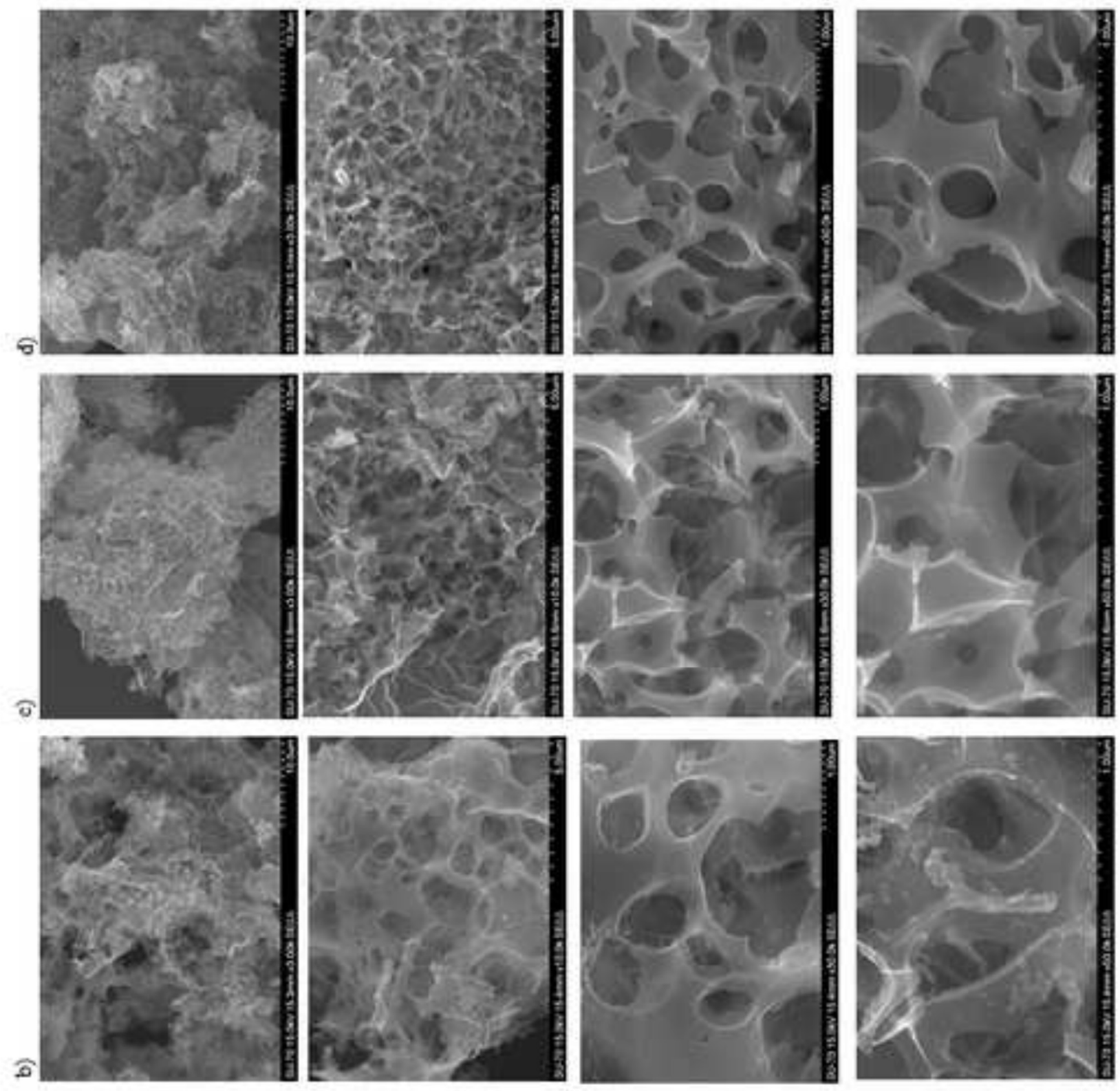

\begin{tabular}{l}
0 \\
8 \\
\hline \\
\hline
\end{tabular}

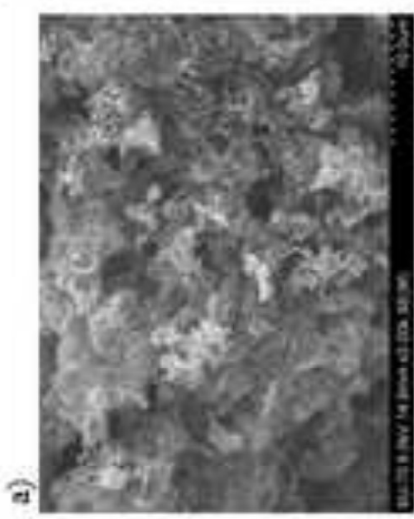

앙

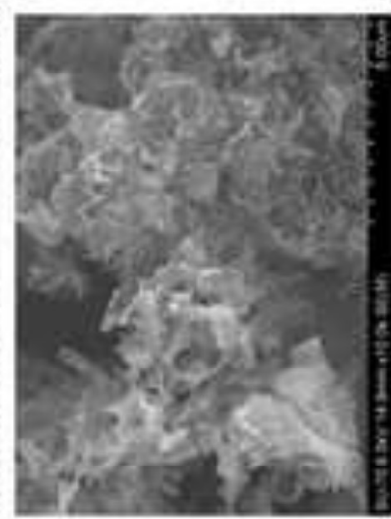

용

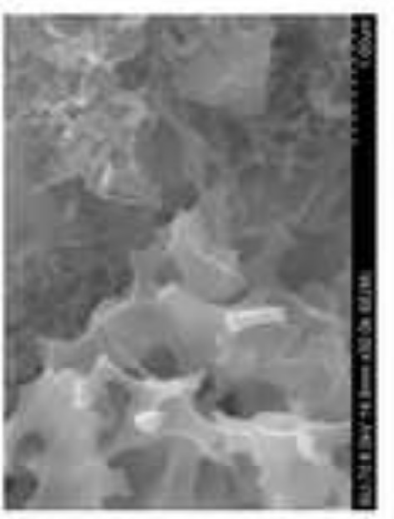

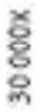

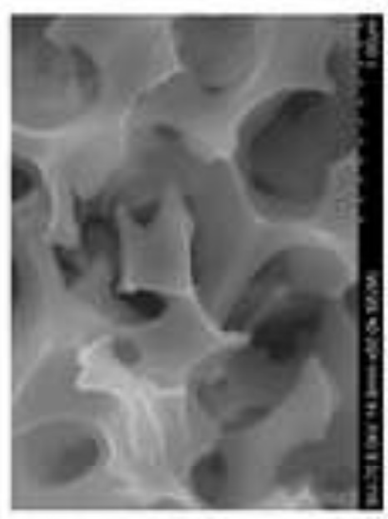

్ㅇㅇ 


\section{Supplementary Material}

\section{Production of highly efficient activated carbons from industrial wastes for the removal of pharmaceuticals from water - a full factorial design}

Guilaine Jaria $^{1}$, Carla Patrícia Silva ${ }^{1}$, João A.B.P. Oliveira ${ }^{1}$, Sérgio M. Santos ${ }^{2}$, María Victoria Gil ${ }^{3}$, Marta Otero ${ }^{4}$, Vânia Calisto $^{1 *}$, Valdemar I. Esteves ${ }^{1}$

${ }^{1}$ Department of Chemistry \& CESAM, University of Aveiro, Campus de Santiago, 3810-193 Aveiro, Portugal

${ }^{2}$ Department of Chemistry \& CICECO, University of Aveiro, Campus de Santiago, 3810-193 Aveiro, Portugal

${ }^{3}$ Instituto Nacional del Carbón, INCAR-CSIC, Francisco Pintado Fe 26, 33011 Oviedo, Spain

${ }^{4}$ Department of Environment and Planning \& CESAM, University of Aveiro, Campus de Santiago, 3810-193 Aveiro, Portugal

*vania.calisto@ua.pt 


\section{Contents}

Analysis of Variance (ANOVA)

Page 3

Table S1 - Analysis of variance (ANOVA) used for the models fitted to the experimental data.

Desirability Function

Page 3

Normal probability distribution plots

Page 4

Figure S1 - Probability plot for the yield of production.

Figure S2 - Probability plot for the adsorption percentage of SMX.

Figure S3 - Probability plot for the adsorption percentage of CBZ.

Figure S4 - Probability plot for the adsorption percentage of PAR.

Figure S5 - Probability plot for TOC.

Figure S6 - Probability plot for $S_{\mathrm{BET}}$.

Table S2 - Analysis of variance (ANOVA) of the obtained responses (least squares method).

Optimization results - Surface response Methodology (RSM)

Page 8

Figure S7 - Response surfaces for the yield of production.

Figure S8 - Response surfaces for the percentage of adsorption of SMX.

Figure S9 - Response surfaces for the percentage of adsorption of CBZ.

Figure S10 - Response surfaces for the percentage of adsorption of PAR.

Figure S11 - Response surfaces for the $S_{\mathrm{BET}}$.

Figure S12 - Response surfaces for the TOC.

Characterization of the $\mathrm{AC}$

Page 12

Table S3 - Boehm's titrations and $\mathrm{pH}_{\mathrm{pcz}}$ results. 


\section{Analysis of Variance (ANOVA)}

Table S1 - Analysis of variance (ANOVA) used for the models fitted to the experimental data.

\begin{tabular}{|c|c|c|c|}
\hline $\begin{array}{l}\text { Variance } \\
\text { source }\end{array}$ & Sum of squares (SS) & $\begin{array}{l}\text { Degrees of } \\
\text { freedom }(v)\end{array}$ & Mean Square (MS) \\
\hline $\begin{array}{l}\text { Regression } \\
\text { (model) }\end{array}$ & $S S_{R E G}=\sum_{i}^{m} \sum_{j}^{n_{1}}\left(\hat{y}_{i}-\bar{y}\right)^{2}$ & $p-1$ & $M S_{R E G}=\frac{S S_{R E G}}{p-1}$ \\
\hline Residuals & $S S_{\text {res }}=\sum_{i}^{m} \sum_{j}^{n_{1}}\left(y_{i j}-\hat{y}_{i}\right)^{2}$ & $n-p$ & $M S_{r e s}=\frac{S S_{r e s}}{n-p}$ \\
\hline Total & $S S_{\text {Total }}=\sum_{i} \sum_{j}\left(y_{i j}-\bar{y}\right)^{2}$ & $n-1$ & \\
\hline \multicolumn{4}{|c|}{$\begin{array}{l}\boldsymbol{n}_{\boldsymbol{i}}-\text { number of observations } \\
\boldsymbol{m} \text { - total number of levels in the design } \\
\boldsymbol{p} \text { - number of parameter of the model (coefficients) } \\
\widehat{\boldsymbol{y}}_{\boldsymbol{i}} \text { - estimated value by the model for the level } \\
\bar{y}_{-}-\text {overall mean } \\
\boldsymbol{y}_{i j}-\text { mean of replicates performed in the same set of experimental conditions }\end{array}$} \\
\hline
\end{tabular}

\section{Desirability Function}

The Derringer function or desirability function, is a multicriteria methodology based on the construction of a desirability function for each individual response, where the measured properties of each response are transformed into a dimensionless individual desirability $\left(d_{i}\right)$ scale ranging between 0 and 1 [1, 2]. Individual desirabilities can be calculated using equation S1, representing a one-side transformation and where $\hat{Y}_{i}$ is the polynomial function obtained for responses, $Y_{i^{*}}$ and $Y_{i}^{*}$ are the minimum and maximum acceptable values, respectively, and $r$ will define the shape of $d_{i}$ and the importance/weight of each response [2, 3].

$$
\left.d_{i}=\left[\frac{\hat{Y}_{i}-Y_{i *}}{Y_{i}^{*}-Y_{i *}}\right]^{r} \quad \text { (equation } \mathrm{S} 1\right)
$$

Therefore, the polynomial function obtained for the responses (fitted response values) is used and the individual desirabilities are combined by a geometric mean:

$$
\mathrm{D}=\left(\mathrm{d}_{\eta} \times \mathrm{d}_{\text {AdsSMX }} \times \mathrm{d}_{\mathrm{AdsCBZ}} \times \mathrm{d}_{\text {AdsPAR }} \times \mathrm{d}_{\text {SBET }} \times \mathrm{d}_{\mathrm{TOC}}\right)^{1 / 6}
$$

The $D$ value gives the overall assessment of the desirability of the combined response levels. In this study a one-sided transformation was applied and the $r$ value was assumed to be 1 [2]. 


\section{Normal probability distribution plots}

Normal probability distribution plots for the six responses were analysed to identify significant effects in an experiment to study the factors that may influence those responses (Figures S1 to S6).

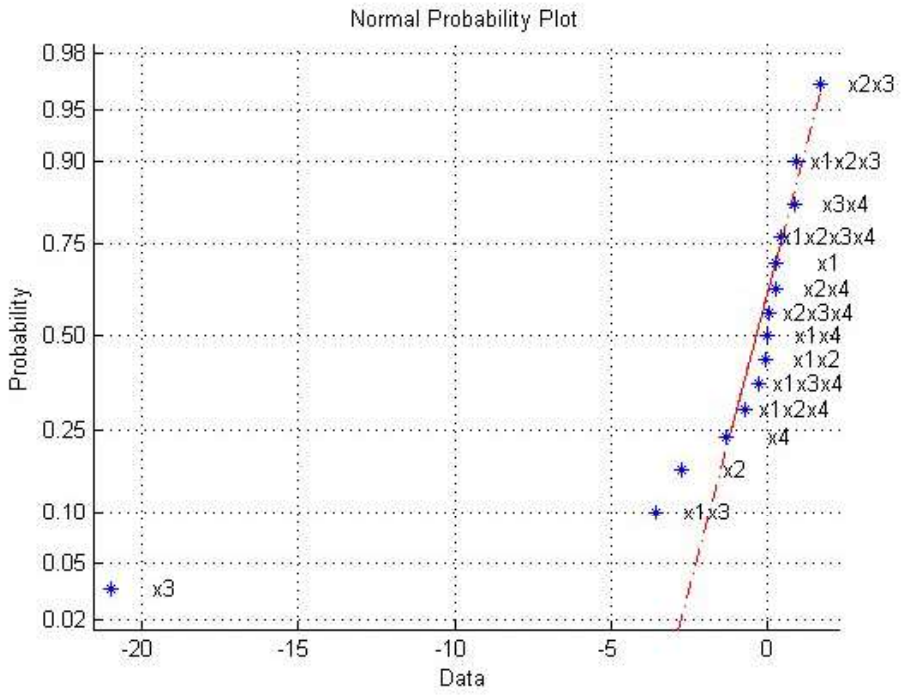

Figure S1 - Probability plot for the yield of production. Equation of the fitted model:

$$
\hat{Y}_{\text {yield }}=15.28-1.38 x_{2}-10.50 x_{3}-1.77 x_{1} x_{3} ; P \text { value: } 3.78 \times 10^{-11}
$$

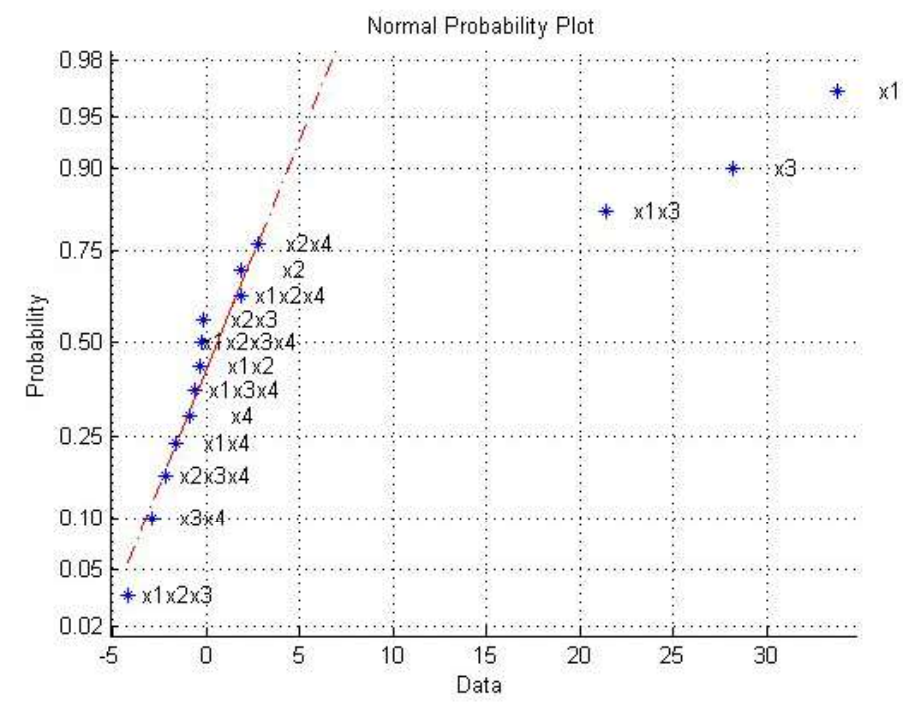

Figure S2 - Probability plot for the adsorption percentage of SMX. Equation of the fitted model:

$$
\hat{Y}_{S M X}=32.47+16.89 x_{1}+14.09 x_{3}+10.70 x_{1} x_{3} ; P \text { value: } 1.95 \times 10^{-10}
$$




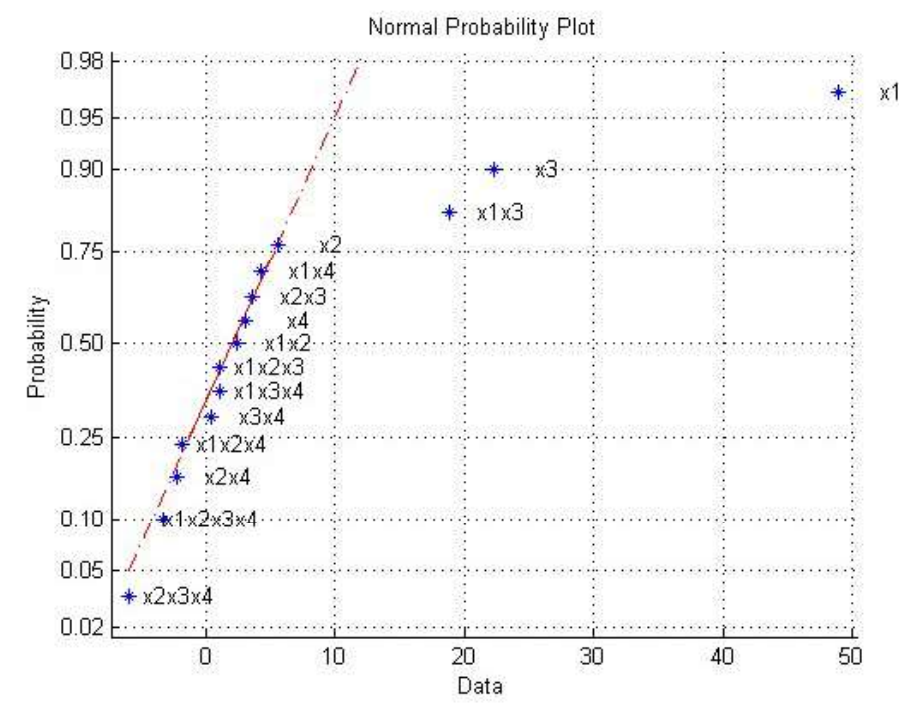

Figure S3 - Probability plot for the adsorption percentage of CBZ. Equation of the fitted model: $\widehat{Y}_{C B Z}=31.11+24.46 x_{1}+11.17 x_{3}+9.45 x_{1} x_{3} ; P$ value: $1.16 \times 10^{-8}$

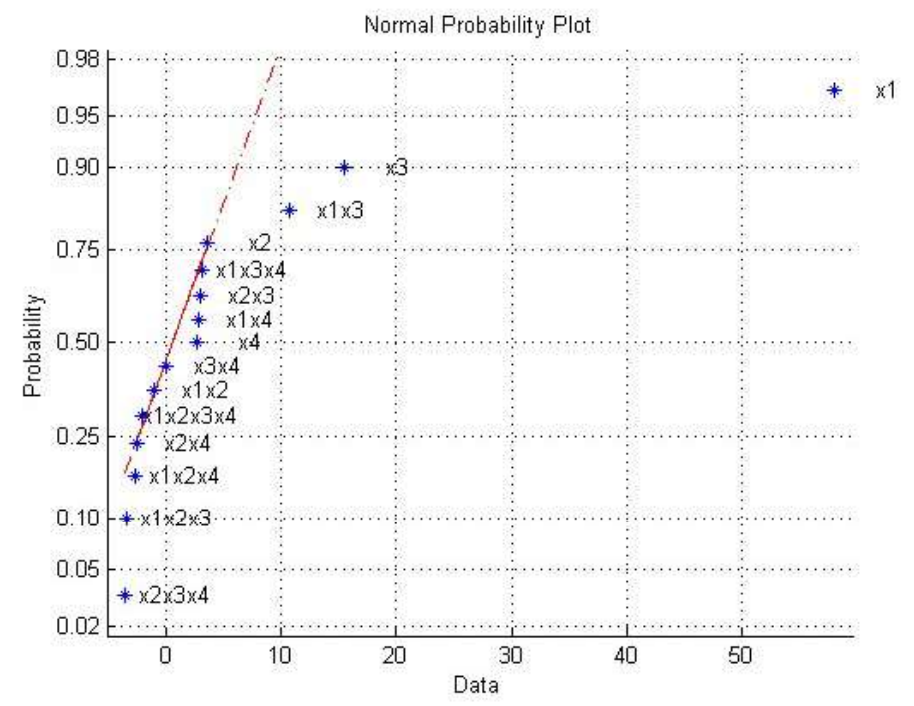

Figure S4 - Probability plot for the adsorption percentage of PAR. Equation of the fitted model: $\hat{Y}_{P A R}=39.07+29.06 x_{1}+7.75 x_{3}+5.36 x_{1} x_{3} ; P$ value: $4.75 \times 10^{-10}$ 


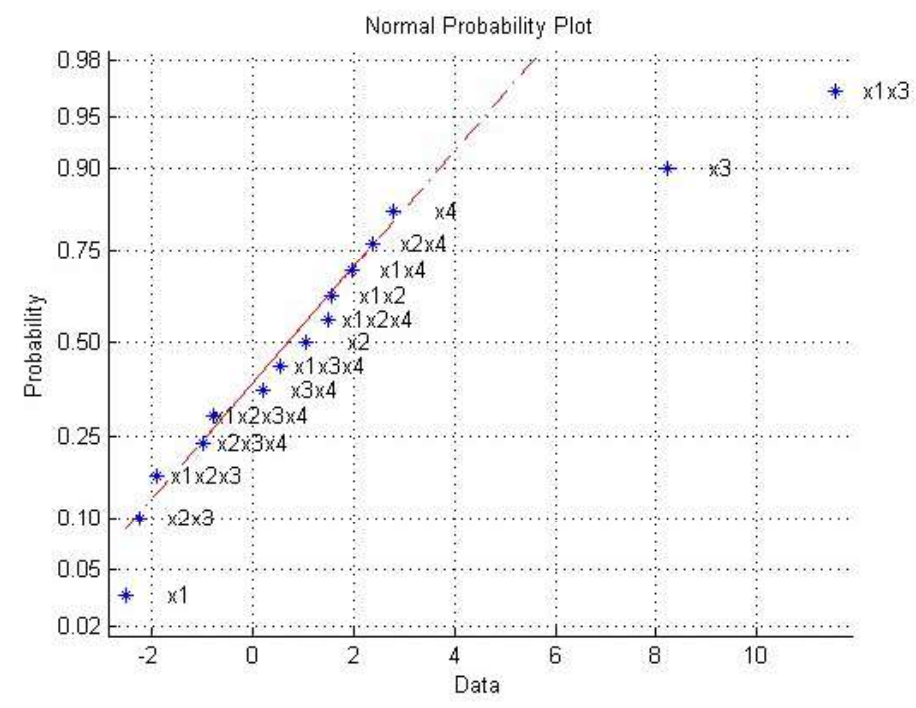

Figure S5 - Probability plot for TOC. Equation of the fitted model:

$\hat{Y}_{T O C}=55.05-1.25 x_{1}+4.12 x_{3}+5.78 x_{1} x_{3} ; P$ value: $2.09 \times 10^{-5}$

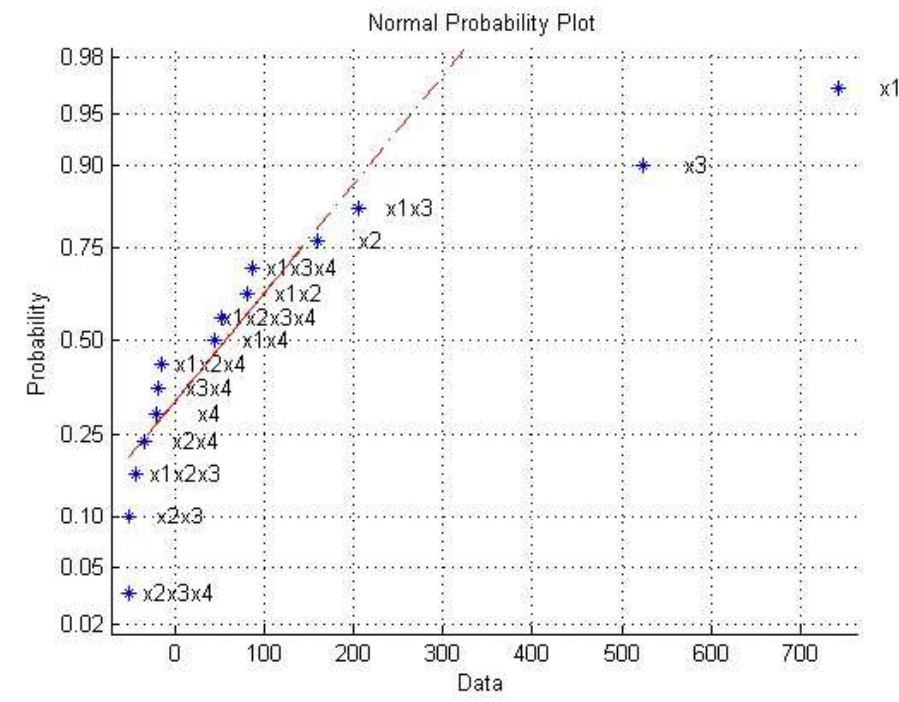

Figure S6 - Probability plot for $S_{\mathrm{BET}}$. Equation of the fitted model:

$\widehat{Y}_{B E T}=795.76+371.44 x_{1}+262.40 x_{3}-25.83 x_{2} x_{3} x_{4} ; P$ value: $3.07 \times 10^{-6}$ 
Table S2 - Analysis of variance (ANOVA) of the obtained responses (least squares method).

\begin{tabular}{|c|c|c|c|c|c|c|}
\hline \multirow{2}{*}{ Response } & \multicolumn{5}{|c|}{ Simple linear regression } & \multirow[b]{2}{*}{ P value } \\
\hline & Source & $d f$ & $S S$ & $M S$ & Fvalue & \\
\hline \multirow[t]{3}{*}{ Yield (\%) } & Regression & 3 & $1.84 \times 10^{3}$ & 613.3 & 256.90 & $3.78 \times 10^{-11}$ \\
\hline & Error & 12 & 28.71 & 2.33 & & \\
\hline & Total & 15 & & & & \\
\hline \multirow[t]{3}{*}{ Ads (\%) SMX } & Regression & 3 & $9.57 \times 10^{3}$ & $3.19 \times 10^{3}$ & 194.43 & $1.95 \times 10^{-10}$ \\
\hline & Error & 12 & 196.97 & 16.41 & & \\
\hline & Total & 15 & & & & \\
\hline \multirow[t]{3}{*}{ Ads (\%) CBZ } & Regression & 3 & $1.30 \times 10^{4}$ & $4.33 \times 10^{3}$ & 96.21 & $1.16 \times 10^{-8}$ \\
\hline & Error & 12 & 540.44 & 45.04 & & \\
\hline & Total & 15 & & & & \\
\hline \multirow[t]{3}{*}{ Ads (\%) PAR } & Regression & 3 & $1.49 \times 10^{4}$ & $4.97 \times 10^{3}$ & 167.06 & $4.75 \times 10^{-10}$ \\
\hline & Error & 12 & 357.44 & 29.79 & & \\
\hline & Total & 15 & & & & \\
\hline \multirow[t]{3}{*}{$S_{\text {BET }}\left(\mathrm{m}^{2} \mathrm{~g}^{-1}\right)$} & Regression & 3 & $3.32 \times 10^{6}$ & $1.11 \times 10^{6}$ & 35.40 & $3.07 \times 10^{-6}$ \\
\hline & Error & 12 & $3.75 \times 10^{5}$ & $3.13 \times 10^{3}$ & & \\
\hline & Total & 15 & & & & \\
\hline \multirow[t]{3}{*}{ TOC (\%) } & Regression & 3 & 830.59 & 276.86 & 24.51 & $2.09 \times 10^{-5}$ \\
\hline & Error & 12 & 135.50 & 11.29 & & \\
\hline & Total & 15 & & & & \\
\hline$d f-$ & dom; $S S-\mathrm{s}$ & of sc & es; $M S-$ & n square & $(S=S S / d f)$ & \\
\hline
\end{tabular}




\section{Optimization results - Surface response methodology (RSM)}

\section{Optimization results for the yield of production}

a)

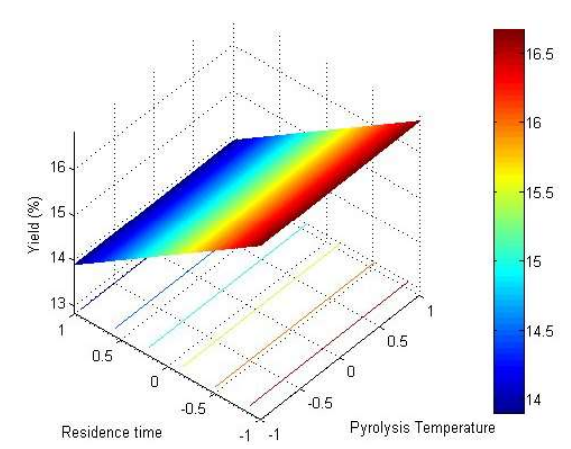

b)

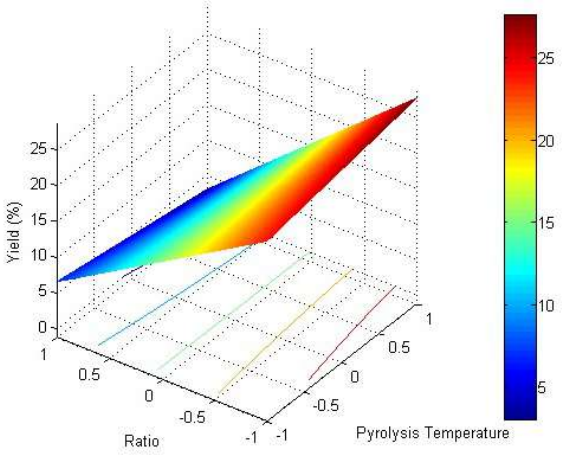

c)

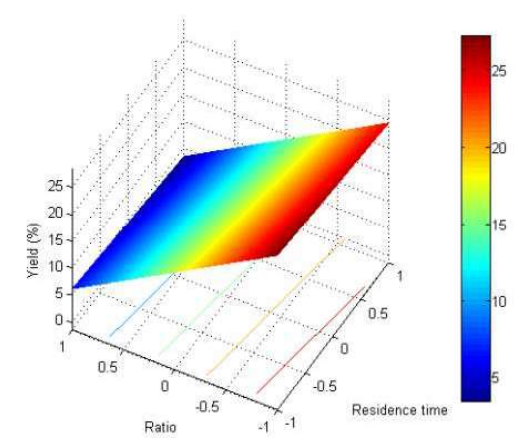

Figure S7 - Response surfaces for the yield concerning: a) residence time $\left(\mathrm{X}_{2}\right)$ versus temperature of pyrolysis $\left(\mathrm{X}_{1}\right)$; b) precursor/activating agent ratio $\left(\mathrm{X}_{3}\right)$ versus temperature of pyrolysis $\left(\mathrm{X}_{1}\right)$; and c) precursor/activating agent ratio $\left(\mathrm{X}_{3}\right)$ versus residence time $\left(\mathrm{X}_{2}\right)$.

\section{Optimization results for the adsorption of SMX}
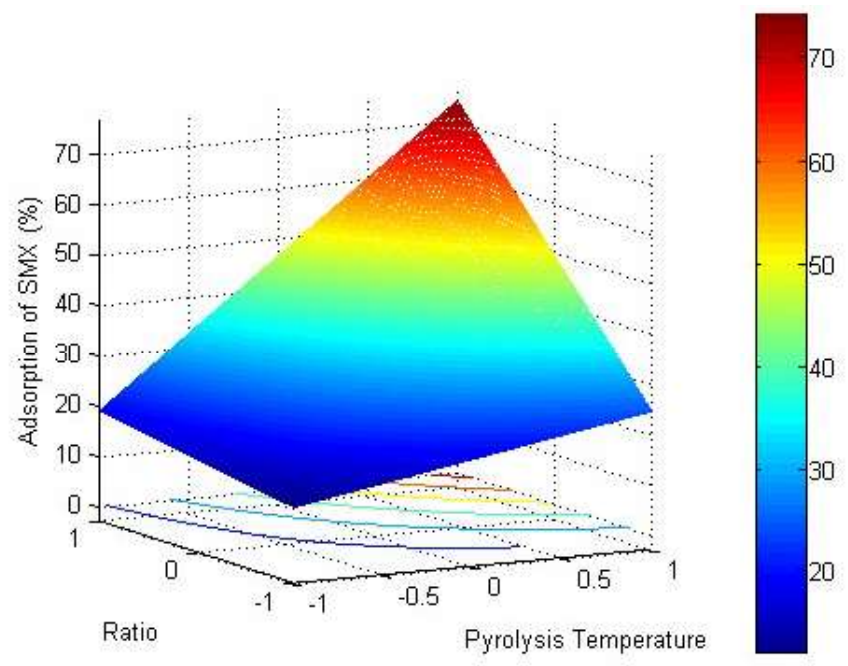

Figure S8 - Response surfaces for the percentage of adsorption of SMX concerning precursor/activating agent ratio $\left(\mathrm{X}_{3}\right)$ versus temperature of pyrolysis $\left(\mathrm{X}_{1}\right)$. 
Optimization results for the adsorption of CBZ
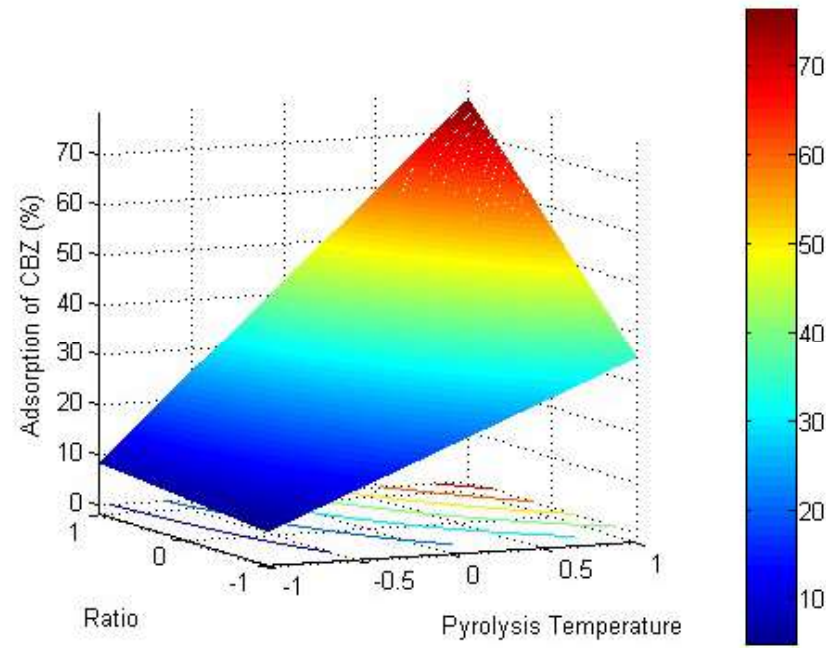

Figure S9 - Response surfaces for the percentage of adsorption of CBZ concerning precursor/activating agent ratio $\left(\mathrm{X}_{3}\right)$ versus temperature of pyrolysis $\left(\mathrm{X}_{1}\right)$; and c) precursor/activating agent ratio $\left(\mathrm{X}_{3}\right)$ versus residence time $\left(\mathrm{X}_{2}\right)$.

\section{Optimization results for the adsorption of PAR}
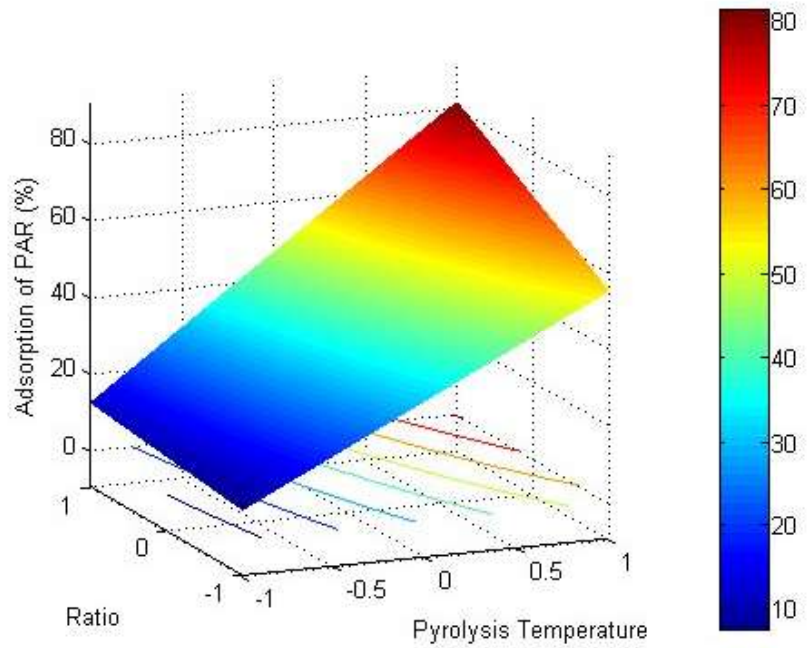

Figure S10 - Response surfaces for the percentage of adsorption of PAR concerning precursor/activating agent ratio $\left(\mathrm{X}_{3}\right)$ versus temperature of pyrolysis $\left(\mathrm{X}_{1}\right)$. 


\section{Optimization results for the $S_{\mathrm{BET}}$}

a)

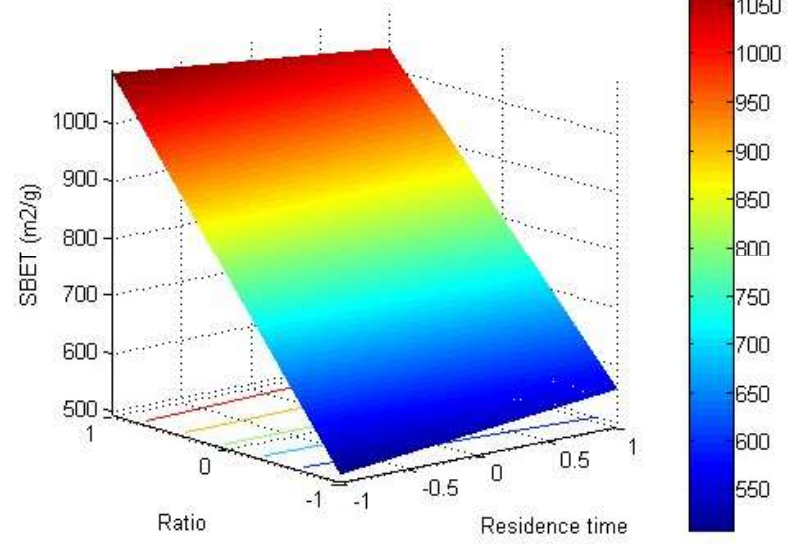

b)

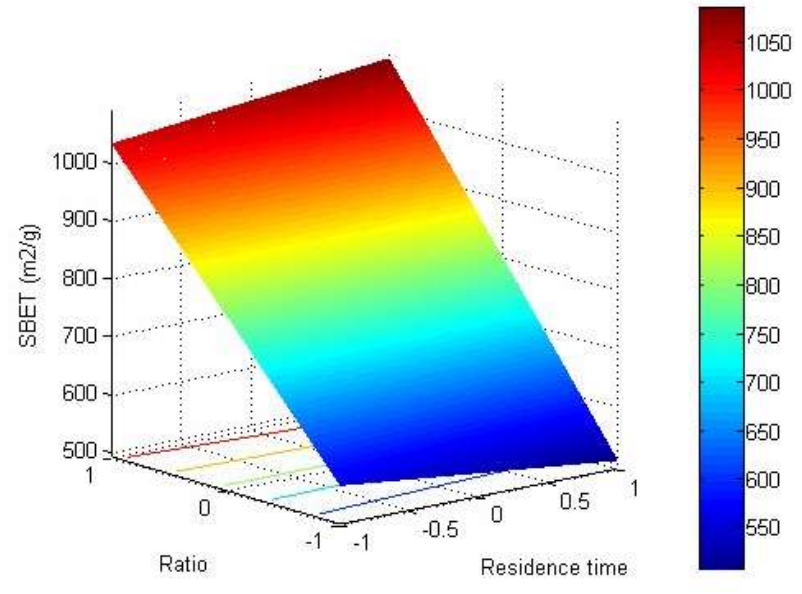

Figure S11 - Response surfaces for the $S_{\mathrm{BET}}$ concerning precursor/activating agent ratio $\left(\mathrm{X}_{3}\right)$ versus temperature of pyrolysis ( $\left.\mathrm{X}_{1}\right)$ with: a) $\mathrm{KOH}$ as activating agent; and b) $\mathrm{K}_{2} \mathrm{CO}_{3}$ as activating agent.

\section{Optimization results for TOC}
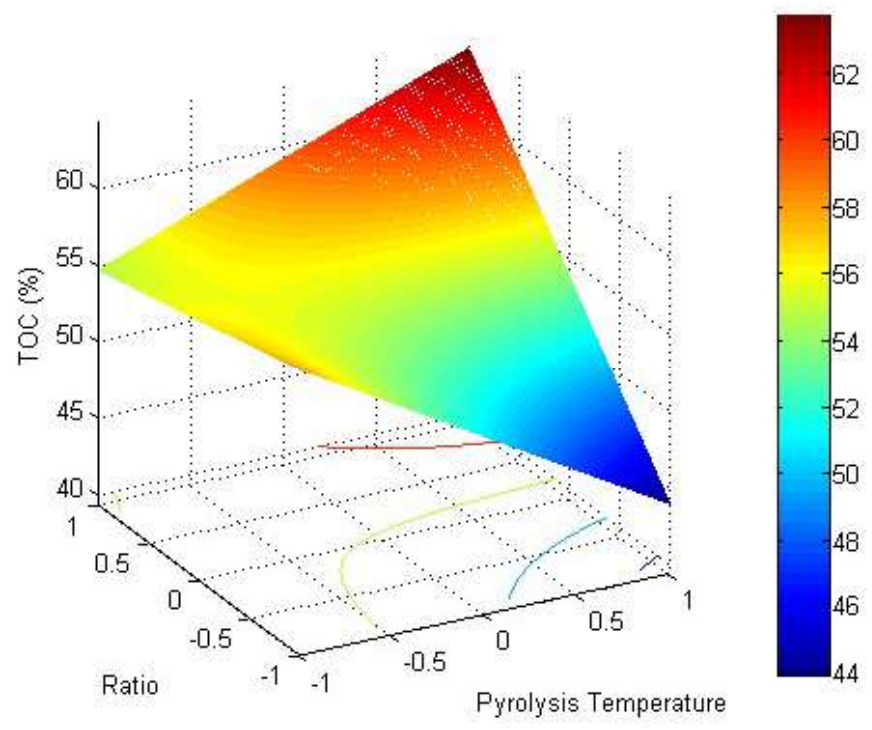

Figure S12 - Response surfaces for the TOC concerning precursor/activating agent ratio $\left(\mathrm{X}_{3}\right)$ versus temperature of pyrolysis $\left(\mathrm{X}_{1}\right)$. 
Figure $\mathrm{S} 7$ evidences that the yield of production is affected by the three effects, $\mathrm{X}_{2}, \mathrm{X}_{3}$, and $\mathrm{X}_{1} \mathrm{X}_{3}$, with $\mathrm{X}_{3}$ having the strongest influence. The better results are obtained for the highest pyrolysis temperature $\left(800{ }^{\circ} \mathrm{C}\right)$ together with the shortest residence time $(60 \mathrm{~min})$ and largest precursor/activating agent ratio (10:1). Relatively to the adsorption of pharmaceuticals, Figures S8, S9 and S10 representing the response surfaces for SMX, CBZ, and PAR respectively, show that the highest percentages of adsorption occur for the highest values $\mathrm{X}_{1}$ and $\mathrm{X}_{3}\left(800^{\circ} \mathrm{C}\right.$ and 1:1). However, in the case of PAR, the influence of the precursor/activating agent ratio for higher temperatures is less pronounced that for the other two pharmaceuticals.

In the case of the $S_{\mathrm{BET}}$ (Figure S11), this response is also mainly affected by the pyrolysis temperature $\left(\mathrm{X}_{1}\right)$ and by the precursor/activating agent ratio $\left(\mathrm{X}_{3}\right)$, with the response increasing for the highest values of both factors, $800{ }^{\circ} \mathrm{C}$ and $1: 1$, respectively. However, residence time together with the precursor/activating agent ratio and the type of activating agent also have some impact in the response. Hence, for higher precursor/activating agent ratios and considering the use of $\mathrm{KOH}$ as activating agent, one can observe that the response is higher for lower residence time (60 min) while in the case of using $\mathrm{K}_{2} \mathrm{CO}_{3}$ as activating agent, the response increase for a higher residence time. For lower precursor/activating agent ratios, the inverse occurs. Despite the little influence of the type of activating agent in the responses for $S_{\mathrm{BET}}$, in general, this factor has not showed to significantly influence the responses. In fact, both activating agents are potassium-based reagents, which is the element considered to be the responsible for the development of porosity. Metallic potassium formed during the gasification process acts as a template due to its intercalation in the graphite-like structure, creating new porosities which highly increase the surface area of the produced carbon material $[4,5]$. Although Ahmed et. al (2012) [5] considered that the amount of potassium atoms released during $\mathrm{KOH}$ activation is higher than with $\mathrm{K}_{2} \mathrm{CO}_{3}$ activation, leading to a higher surface area of the carbons produced by $\mathrm{KOH}$ activation, in 
this study, this was not evident, with both activating agents resulting in very similar $S_{\mathrm{BET}}$ (Table 1 ). An important aspect of this study, is that the chemical activation was performed at a precursor/activating agent weight ratio of 1 when specially, in the case of $\mathrm{KOH}$, the chemical activation usually uses a $\mathrm{KOH} /$ precursor weight ratio between 2 and 4 [6-8]. In this work, the best results were, as expected, obtained for the higher ratio weight (1:1) tested, however is important to highlight that the heat treatment (pyrolysis) and activation are performed in one step only, reducing the environmental impact of the production and also the production costs.

At last, for the TOC (Figure S12), the results are very interesting, with the interaction of pyrolysis temperature and precursor/activating agent ratio, not showing an apparent linear relationship, but evidencing highest values of response for the highest temperature of pyrolysis and for the highest precursor/activating agent ratio.

\section{Characterization of the $A C$}

Table S3 - Boehm's titrations and $\mathrm{pH}_{p c z}$ results. Boehm's titrations were performed using a concentration of carbon material of $10 \mathrm{~g} \mathrm{~L}^{-1}$. The $\mathrm{pH}_{p c z}$ was determined using a concentrations of carbon material of $0.01 \mathrm{~g} \mathrm{~L}^{-1}$.

\begin{tabular}{|c|c|c|c|c|c|c|}
\hline \multirow{3}{*}{$\mathbf{A C}$} & \multicolumn{5}{|c|}{ Amount of functional groups $\left(\mathrm{mmol} \mathrm{g}^{-1}\right)$} & \multirow{3}{*}{$\begin{array}{c}p H_{p z c} \\
0.01 g L^{-1}\end{array}$} \\
\hline & \multirow{2}{*}{$\begin{array}{c}p K a<6.37 \\
\text { carboxyls }\end{array}$} & \multicolumn{2}{|c|}{$6.37<p K a<10.25$} & \multirow{2}{*}{$\begin{array}{c}\text { Total } \\
\text { acid }\end{array}$} & \multirow{2}{*}{$\begin{array}{l}\text { Total } \\
\text { basic }\end{array}$} & \\
\hline & & phenol & lactones & & & \\
\hline 3 & 0.05 & 0.99 & 0.49 & 1.53 & 0.25 & 5.45 \\
\hline 4 & -0.11 & 1.20 & 0.35 & 1.44 & 0.72 & 6.16 \\
\hline 6 & 1.04 & 1.31 & 0.26 & 2.61 & 0.04 & 4.60 \\
\hline 7 & -0.27 & 1.50 & 0.03 & 1.26 & 0.12 & 5.12 \\
\hline
\end{tabular}




\section{Supplementary References}

[1] M.A. Bezerra, R.E. Santelli, E.P. Oliveira, L.S. Villar, L.A. Escaleira, Response surface methodology (RSM) as a tool for optimization in analytical chemistry, Talanta, 76 (2008) 965-977.

[2] G. Derringer, R. Suich, Simultaneous Optimization of Several Response Variables, Journal of Quality Technology, 12 (1980).

[3] K. Ennaciri, A. Baçaoui, M. Sergent, A. Yaacoubi, Application of fractional factorial and Doehlert designs for optimizing the preparation of activated carbons from Argan shells, Chemometrics and Intelligent Laboratory Systems, 139 (2014) 48-57.

[4] H. Marsh, F. Rodríguez-Reinoso, Activated Carbon, First ed., Elsevier, England, 2006.

[5] M.J. Ahmed, S.K. Theydan, Adsorption of cephalexin onto activated carbons from Albizia lebbeck seed pods by microwave-induced $\mathrm{KOH}$ and $\mathrm{K}_{2} \mathrm{CO}_{3}$ activations, Chemical Engineering Journal, 211-212 (2012) 200-207.

[6] T.J. Bandosz, Activated Carbon Surfaces in Environmental Remediation, First ed., Elsevier, New York, 2006.

[7] M.A. Lillo-Ródenas, J.P. Marco-Lozar, D. Cazorla-Amorós, A. Linares-Solano, Activated carbons prepared by pyrolysis of mixtures of carbon precursor/alkaline hydroxide, Journal of Analytical and Applied Pyrolysis, 80 (2007) 166-174.

[8] J. Alcañiz-Monge, M.J. Illan-Gomez, Insight into hydroxides-activated coals: chemical or physical activation?, Journal of Colloid and Interface Science, 318 (2008) 35-41. 